\title{
Oral Administration of Heat-Treated Lactobacilli Modifies the Murine Microbiome and Reduces Citrobacter Induced Colitis
}

\author{
Alicja K. Warda', Pedro H. de Almeida Bettio ${ }^{1}$, Cara M. Hueston ${ }^{1}$, Giulio Di Benedetto ${ }^{1}$, \\ Adam G. Clooney ${ }^{1}$ and Colin Hill',2* \\ ${ }^{1}$ APC Microbiome Ireland, University College Cork, Cork, Ireland, ${ }^{2}$ School of Microbiology, University College Cork, Cork, \\ Ireland
}

\section{OPEN ACCESS}

Edited by:

Markus M. Heimesaat,

Charité Medical University of Berlin,

Germany

Reviewed by:

Luis Vitetta

University of Sydney, Australia

Andreas Kupz,

James Cook University, Australia

${ }^{*}$ Correspondence:

Colin Hill

c.hill@ucc.ie

Specialty section:

This article was submitted to

Microbial Immunology,

a section of the journal

Frontiers in Microbiology

Received: 13 September 2019

Accepted: 14 January 2020

Published: 30 January 2020

Citation:

Warda AK, de Almeida Bettio PH,

Hueston CM, Di Benedetto G,

Clooney AG and Hill C (2020) Oral

Administration of Heat-Treated

Lactobacilli Modifies the Murine Microbiome and Reduces Citrobacter Induced Colitis.

Front. Microbiol. 11:69.

doi: 10.3389/fmicb.2020.00069
Significant evidence supports a relationship between the gut microbiome, inflammation, host response, and health, including the finding that a number of disorders are associated with disruption of the microbiome. In these disorders, a number of dietary interventions (including prebiotics, live probiotics, or heat-killed microbes) have been proposed to be curative or preventative agents. The use of heat-killed microbes has a number of benefits over living organisms, including reduced infection risk in vulnerable individuals, extended shelf life and the potential for use in combination with antimicrobial agents. We previously reported that murine chow supplemented with 5\% ADR-159, a heat-treated fermentate generated by two Lactobacillus strains, altered both behavior and the microbiome of male mice. Now we show that ADR-159 fed female mice also display a similar microbiome shift as determined by $16 \mathrm{~S}$ rDNA analysis. In particular, we observed a reduction of levels of Turicibacter and Clostridium sensu stricto. These subtle changes in the bacterial component of the microbiome were mirrored by changes in the virome. Extended consumption of the ADR-159 diet had no negative effect on general health and lipocalin 2 levels (LCN2; a proxy for inflammation), but we observed increased $\mathrm{IL}-17 f$ and decreased IL-12 $\alpha$ expression in the colon and decreased short chain fatty acid levels in the ADR-159 fed animals. Four weeks into the diet, half of the animals were dosed with Citrobacter to determine the effect of ADR-159 on infection and on pathogen induced colitis. Overall, our results suggest that while the ADR-159 diet does not prevent Citrobacter infection, it had an effect on Citrobacter-induced inflammation. In contrast to animals fed standard chow, ADR-159 fed animals did not show a reduction of small intestine length and increase of colon crypt depth, which occurred in control mice. These microbiological, histological, and immunological results provide evidence to support the impact of heat-treated microorganisms and their metabolites on the murine microbiome and health.

Keywords: microbiome, dead probiotics, inflammation, pharmabiotics, Citrobacter 


\section{INTRODUCTION}

Significant evidence supports the relationship between the gut microbiome, inflammation, host response, and health (Pedersen et al., 2016; Dinan and Cryan, 2017; Kelly et al., 2017; Giron and Quigley, 2018). Disruption of the microbiome can lead to changes in microbial metabolism and consequently host metabolism (Belizario et al., 2018). The aforementioned changes can also affect inflammatory responses and adaptive immunity and can even contribute to metabolic disorders (Belizario et al., 2018). Inflammation is part of a multifaceted biological response to pathogens, damaged cells or irritants (Chen et al., 2018). Inflammatory processes can clear necrotic cells and damaged tissues and initiate tissue repair (Ferrero-Miliani et al., 2007). While acute inflammation in healthy individuals is considered an indication of healing, it can cause a major disturbance when it is inappropriate or becomes chronic. For example, Inflammatory Bowel Disease (IBD) is a chronic inflammatory condition affecting the gastrointestinal (GI) tract, and includes Crohn's Disease (CD) and ulcerative colitis (UC) (Rubin et al., 2012). Normally, dead or damaged cells in the gastrointestinal tract are rapidly eliminated while new ones are constantly generated (Kim et al., 2010). A typical cell turnover of $4-5$ days is associated with a basal level of inflammation that facilitates maintenance of the intestinal barrier and prevents an excessive inflammatory response (Kim et al., 2010). In the absence of the microbiome, cell turnover is slowed; one of the effects of this is an excessive inflammatory response (Kim et al., 2010). During bacterial infection the balance of cell renewal can be disturbed, resulting in rapid proliferation and crypt hyperplasia (Kim et al., 2010). This phenomenon is commonly observed in animal models of GI infection and inflammation. A frequent cause of bacterial infection and intestinal inflammation include members of the Proteobacteria; especially food-born Campylobacter, Salmonella, Shigella, enteroinvasive and enterohemorrhagic Escherichia coli (EIEC and EHEC, respectively), and Yersinia species (Papaconstantinou and Thomas, 2007). In murine models the presence of certain bacteria, including Proteus mirabilis, Klebsiella pneumonia, and Bilophila wadsworthia has been associated with colitis (Weingarden and Vaughn, 2017). Bacteria such as Citrobacter rodentium, Helicobacter pylori, Mycobacterium avium, and Salmonella enterica serovar Typhimurium are commonly used in animal models to trigger colitis-like conditions (Jiminez et al., 2015). In particular, the C. rodentium infection is used as a model for several important human intestinal disorders, including $\mathrm{CD}, \mathrm{UC}$, and colon tumorigenesis (Collins et al., 2014b). Infection of mice with C. rodentium results in the colonization of the large intestine and subsequent mild inflammation that is maintained after the pathogen has been cleared (Wiles et al., 2004).

Citrobacter has been associated with a T helper 1 (Th1) and a more potent Th17 cell response (Higgins et al., 1999; Mangan et al., 2006; Collins et al., 2014b). A number of Interleukins (IL-) and cells create an interconnection between the innate and adaptive immune systems, allowing the host to overcome the infection. The Th1 cell response in the gut is characterized by the production of interferon- $\gamma($ IFN- $\gamma)$ and tumor necrosis factor (TNF) (Collins et al., 2014b). TNF is both a pro- and anti-inflammatory cytokine involved in the development of autoimmune diseases and cancer, as well as playing a role in protection against infectious pathogens (Mehta et al., 2018). The Th17 cell response is characterized by the production of IL-17a, IL-17f, IL-22, and IL-26 (Li et al., 2018). A robust expression of pro-inflammatory cytokines (IL-17a, IL-17f, IL-22, and IFN$\gamma$ ) peaking at day 8 and subsequently declining at day 11 were reported for Citrobacter infection (Hoffmann et al., 2009). At the same time, IL-6 has been reported to provide protection against the colonic mucosal ulceration caused by Citrobacter (Dann et al., 2008), while IL-1 $\beta$ has been shown to contribute to Citrobacter clearance and minimize tissue damage (Alipour et al., 2013). C. rodentium is a known attaching and effacing $(\mathrm{A} / \mathrm{E})$ pathogen that induces a coordinated response involving multiple components of the mucosal defense system (Collins et al., 2014b).

The potential of heat-killed microorganisms to provide a benefit to humans or animals has been examined in a number of studies (Taverniti and Guglielmetti, 2011; de Almada et al., 2016; Warda et al., 2018). These heat-killed preparations have also been termed "paraprobiotics," "post-biotics," or "ghost probiotics" (Taverniti and Guglielmetti, 2011; de Almada et al., 2016). Such preparations containing heat-killed microorganisms have been reported to confer health benefits including treatment of diarrhea, colitis, inflammation, respiratory diseases, intestinal lesions, as well as modification of the immune system and impact on the intestinal microbiome and bacterial translocation (de Almada et al., 2016). The administration of microorganisms that have been subjected to a high temperature heat treatment could be advantageous over living microbes in terms of (i) extended shelf life, (ii) not being affected by high or low temperature excursions (allowing for product to be more readily sanitized or even sterilized), (iii) storage and transportation at ambient temperatures, with a consequent potential for uses in less developed regions. Additional advantages include (iv) limited infection risk in vulnerable individuals, ( $\mathrm{v}$ ) no translocation of genetic material for those preparations subjected to a sufficient heating step, and (vi) the ability to be used in combination with antimicrobial agents (Taverniti and Guglielmetti, 2011; de Almada et al., 2016; Warda et al., 2018).

ADR-159 contains a heat-treated fermentate and microbial biomass generated by two Lactobacillus strains, Lactobacillus fermentum, and Lactobacillus delbrueckii. In previous work, we have demonstrated that an ADR-159 supplemented diet is capable of modifying the microbiome and behavior in healthy male mice (Warda et al., 2018). We used the C. rodentium model of infection and colitis to elucidate the role of ADR-159 in infection and inflammation.

\section{MATERIALS AND METHODS}

\section{Diet Preparation}

The composition of the ADR-159 preparation has been previously described as follows (Warda et al., 2018): ADR159 contains a co-fermentate of Lactobacillus fermentum and Lactobacillus delbrueckii, which also includes culture medium 
(lactose monohydrate, casein peptone, yeast extract, sodium acetate, dipotassium phosphate). The fermentate is subjected to an extended high-temperature treatment post-production. One gram of ADR-159 contains a minimum of 60 billion intact bacterial cells. ADR-159 is a proprietary product produced and supplied by Adare Pharmaceuticals SAS, Route de Bu, 78550, Houdan, France. ADR-159 was incorporated into standard mice chow [2018S Teklad Global 18\% Protein Rodent Diet (Envigo)] to a final concentration of $5 \%$, equivalent to approximately $3 \times 10^{9}$ cell bodies per gram of chow.

\section{Animal Experiment \\ Animals and Housing Conditions}

Animals and housing conditions used were similar to those previously reported (Warda et al., 2018) with the following modifications. Briefly, 54 eight-week old female C57BL/6 mice (Envigo, United Kingdom) were randomly assigned in groups of 3 or 4 animals to 14 enriched (cardboard tubes and shredded paper) individually ventilated cages for 1 week of acclimatization at $21 \pm 1^{\circ} \mathrm{C}$ and at a humidity of $55 \pm 10 \%$, and with a $12 \mathrm{~h}$ light/dark cycle. Animals were fed ad libitum with 2018S Teklad Global 18\% Protein Rodent Diet (Envigo; 8 cages/30 animals) or the same diet supplemented with 5\% ADR-159 (6 cages/24 animals) (Figure 1). Each week animals were weighed and feed consumption was controlled by weighing contents of the food hoppers. Additionally, fecal samples were acquired for 16S rRNA gene metagenomics, phageomics and lipocalin analysis.

All experiments were performed in accordance with the European Directive 2010/63/EU and approved by the Animal
Experimentation Ethics Committee of University College Cork and Health Products Regulatory Authority under HPRA Project License AE19130/P060. All efforts were made to reduce the number of animals and to minimize suffering.

\section{Citrobacter Infection}

Citrobacter rodentium ICC180, carrying a luminescent tag, was streaked from $-80^{\circ} \mathrm{C}$ stock on Luria agar containing $50 \mu \mathrm{g} / \mathrm{ml}$ kanamycin and $50 \mu \mathrm{g} / \mathrm{ml}$ nalidixic acid $(\mathrm{LB}+\mathrm{Kan}+\mathrm{Nal})$ followed by overnight incubation at $37^{\circ} \mathrm{C}$. A single colony was used to inoculate $25 \mathrm{ml}$ of $\mathrm{LB}+\mathrm{Kan}+\mathrm{Nal}$ broth in a $50 \mathrm{ml}$ tube in duplicate, followed by static overnight incubation at $37^{\circ} \mathrm{C}$. Grown cultures were gently centrifuged (10 $\mathrm{min}$ at $5000 \mathrm{rpm}$ ), washed with PBS and resuspended in $2.5 \mathrm{ml}$ of PBS.

Six animals were orally gavaged with $200 \mu \mathrm{l}$ of $C$. rodentium lab grown cell suspension (see above) to increase infection by adapting bacteria to the GI environment. Stomach $\mathrm{pH}$ was not neutralized prior to infection. Weight and C. rodentium shedding by pre-infection animals was monitored on a daily basis. On day 9 post-gavage feces of infected animals were collected, resuspended in PBS ( $1 \mathrm{~g}$ in $10 \mathrm{ml}$ ), centrifuged (10 min at $4000 \mathrm{rpm}$ ), washed twice in PBS. Consequently, a 1 in 10 fecal solution containing $C$. rodentium cells $\left(8.1 \times 10^{6} \mathrm{CFU} / \mathrm{ml}\right)$ was obtained.

After 4 weeks of the diets, 48 animals were orally dosed with $200 \mu \mathrm{l}$ of PBS (control animals) or $200 \mu \mathrm{l}$ fecal solution containing $1.62 \times 10^{6} \mathrm{CFU}$ of $C$. rodentium (see above). Initially only 3 out of 24 animals were shedding C. rodentium, therefore at day six post-first dosing, animals received a second dose. In this case, $\mathrm{PBS}$ or $1.18 \times 10^{9} \mathrm{CFU}$ of C. rodentium cells grown
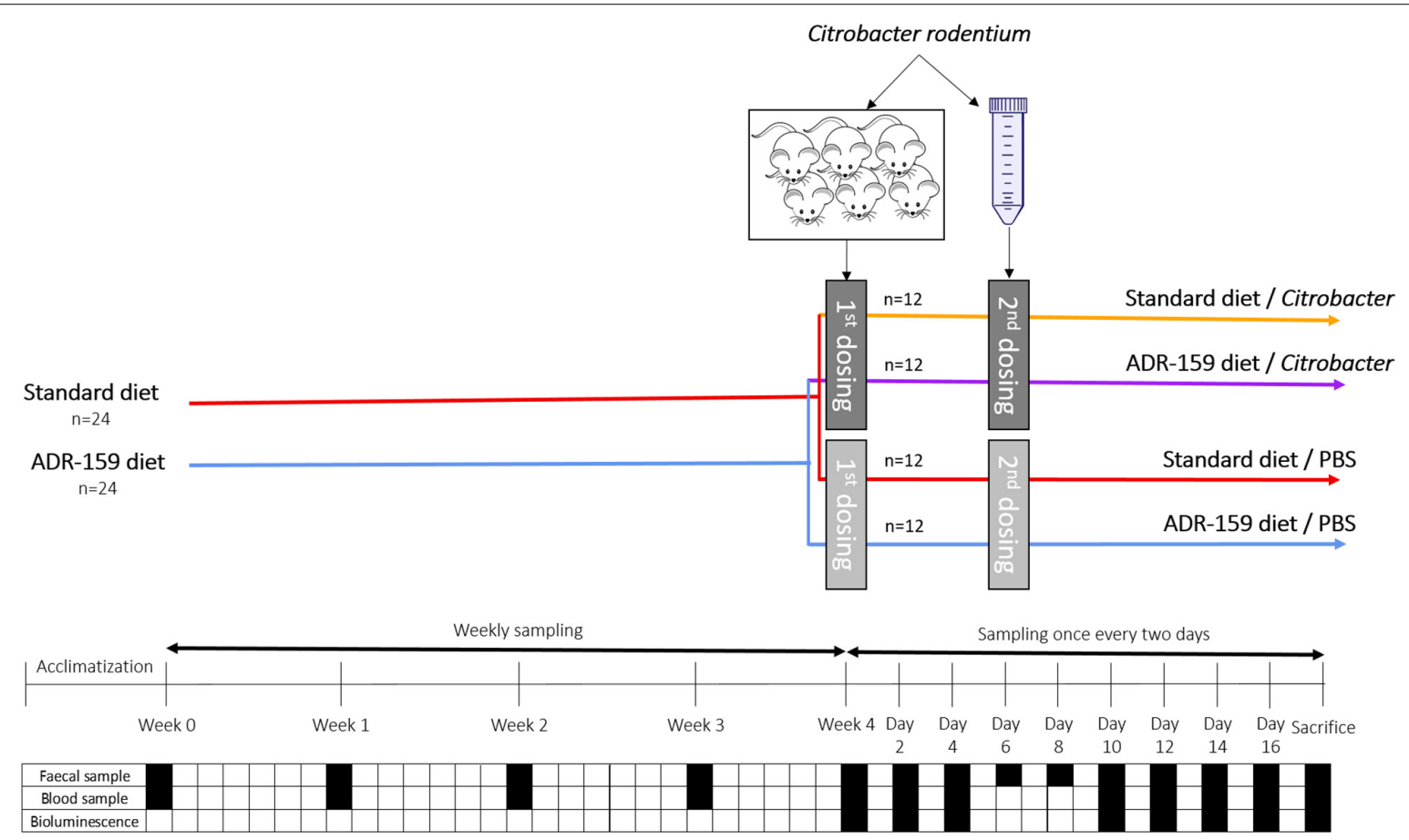

FIGURE 1 | Schematic representation of C. rodentium animal experiment. Dark gray indicates dosing containing Citobacter while light gray indicated dosing of animals with PBS. Black square indicates sampling, while white square indicates no sampling of given material type. 
in laboratory media (see above) were delivered via oral gavage. Following the second dose, all animals shed C. rodentium.

Murine feces were collected on a regular basis, followed by pellet resuspension in PBS in a 1:20 ratio. Re-suspended feces were serially diluted in PBS and $100 \mu \mathrm{l}$ was duplicate plated on $\mathrm{LB}+\mathrm{Kan}+\mathrm{Nal}$. This was followed by overnight incubation at $37^{\circ} \mathrm{C}$ and colony counting.

After 8 weeks of the diets, mice were sacrificed and trunk blood was collected. Organ lengths and weights were measured, followed by collection of cecum content for SCFA analysis. Distal fragments of colon and ileum of approximately $2.5 \mathrm{~cm}$ were Swiss rolled, dehydrated, paraffin embedded and stored until histology analysis. Two additional fragments of approximately $2.5 \mathrm{~cm}$ of colon and ileum were preserved in RNA later at $-80^{\circ} \mathrm{C}$ for $\mathrm{qPCR}$.

\section{Histology}

\section{Tissue preparation for histology}

Sections of colon and ileum (approximately $2.5 \mathrm{~cm}$ long) were rolled and kept overnight in 10\% formalin, followed by 2 weeks in $70 \%$ ethanol for fixation. Tissue was then dehydrated and embedded in paraffin wax (100\% ethanol $2.5 \mathrm{~h}$; $100 \%$ ethanol $1.5 \mathrm{~h} ; 1: 1100 \%$ ethanol:histolene $1 \mathrm{~h}$; histolene $2 \mathrm{~h}$; histolene 2 h; paraffin 2 h; paraffin 2 h) using Leica TP1020 Histokinette. Tissue was cut onto slides in $10 \mu \mathrm{m}$ sections on a rotary microtome (Leica, RM2135), then stored at room temperature until histology commenced.

\section{Measurement of colon crypt and ileum villi length}

Sections of the colon and ileum were de-waxed using three $10 \mathrm{~min}$ incubations in Histochoice clearing agent (Amresco, H103). Sections were then rehydrated through a series of ethanol concentrations $(100,95,90,70 \%)$ for $2 \mathrm{~min}$ each, then rinsed with water for $5 \mathrm{~min}$. Sections were then placed into Mayer's Hematoxylin (VWR, 10047005) for $5 \mathrm{~min}$, followed by a $5 \mathrm{~min}$ water rinse. Sections were then placed in Eosin (VWR, 10047003) for $30 \mathrm{~s}$, rinsed with water, and dehydrated through a series of ethanol concentrations $(70,90,95,100 \%)$ for 2 min each. Sections were then placed in two $2 \mathrm{~min}$ incubations of Histochoice, then coverslipped with DPX mounting medium (Sigma, 06522). Sections were imaged at $40 \mathrm{X}$ using a brightfield microscope (Olympus DP71), and 5 crypt and 5 villi length were measured for each animal ( $n=8$ for healthy animals and $n=12$ for Citrobacter infected animals) using ImageJ software (NIH), and the values were averaged per animal for each tissue type. All measurements were conducted in blind to groups.

\section{Quantification of Fecal Lipocalin 2 (LCN2) by ELISA and Determination of Colitis Incidence}

LCN2 levels were estimated in the fecal supernatants using Duoset murine LCN2 ELISA kit (R\&D Systems, Minneapolis, Minnesota) as described previously (Chassaing et al., 2012), with following modifications. Frozen fecal samples were resuspended in PBS containing $0.1 \%$ Tween 20 to a final concentration of $100 \mathrm{mg} / \mathrm{ml}$. A homogenous fecal suspension was generated by bead beating (FastPrep ${ }^{\circledR}-24$, MP Biomedicals, United States) for a total of $20 \mathrm{~min}$. These samples were then centrifuged (DragonLab, China) for $10 \mathrm{~min}$ at $14,000 \times \mathrm{g}$ and $4^{\circ} \mathrm{C}$. Clear supernatants were collected and stored at $-20^{\circ} \mathrm{C}$ until analysis. Ten to thousand time diluted samples were used in the assay according to the manufacturers' instructions. The colorimetric peroxidase substrate tetramethylbenzidine was quantified by measurement of absorbance at 450 and $540 \mathrm{~nm}$ (SpectraMax M3, Molecular Devices). Analysis was done using four parameter logistic curve ${ }^{1}$.

\section{Colon Cytokine Expression RNA isolation from tissues}

Approximately $30 \mathrm{mg}$ of colon tissue preserved in RNAlater at $-80^{\circ} \mathrm{C}$ was transferred into MagNA Lyser Green Beads (Roche) together with $600 \mu \mathrm{l}$ of buffer RLT supplemented with $6 \mu \mathrm{l}$ of 2-mercaptoethanol ( $\beta$-ME). Tubes were subjected to MagNA Lyser (Roche) twice for $15 \mathrm{~s}$ at 6000. Lysate was centrifuged for $3 \mathrm{~min}$ at maximum speed $(10,000 \times g)$. Supernatant was mixed with $70 \%$ ethanol in 1 to 1 ratio. Sample, including any precipitate, was transferred onto RNeasy Mini spin column and centrifuged for $30 \mathrm{~s}$ at $10,000 \times \mathrm{g}$. Column was washed with 700 $\mu l$ of Buffer RW1 and twice with $500 \mu l$ Buffer RPE. RNA was eluted in $100 \mu \mathrm{l}$ of RNase-free water (repeated elution). Isolated RNA sample was DNAse treated by adding $11 \mu$ l of 10X Turbo DNAse Buffer, $3 \mu \mathrm{l}$ of Turbo DNAse (Ambion) and incubated for $30 \mathrm{~min}$ at $37^{\circ} \mathrm{C}$. Second dose of $3 \mu \mathrm{l}$ of Turbo DNAse was added followed by incubation for $30 \mathrm{~min}$ at $37^{\circ} \mathrm{C}$. Next $22 \mu \mathrm{l}$ of DNAse Inactivation Reagent was added and incubated for $5 \mathrm{~min}$ at room temperature to inactivate the enzyme. Finally, samples were centrifuged for $2 \mathrm{~min}$ at $10,000 \times \mathrm{g}$, supernatant was transferred to fresh tubes and concentration of RNA was measured using Qubit BR RNA Assay Kit (Invitrogen/Thermo Fisher Scientific). RNA was stored at $-80^{\circ} \mathrm{C}$.

\section{qPCR analysis of cytokine expression}

Reverse transcription was performed in 10 replicates for each sample individually using $2 \mu \mathrm{g}$ in $10 \mu \mathrm{l}$ of RNA per reaction. Each reaction of $20 \mu \mathrm{l}$ contained $4 \mu \mathrm{l}$ of 5X Transcriptor buffer, $1 \mu \mathrm{l}$ of 1:1 mix of Transcriptor Reverse Transcriptase (Roche) and Protector RNase Inhibitor (Roche), $2 \mu \mathrm{l}$ of $10 \mathrm{mM}$ dNTP mix (Roche), and $3 \mu \mathrm{l}$ of Random Primers (Roche). Following the incubation for $10 \mathrm{~min}$ at $25^{\circ} \mathrm{C}, 30 \mathrm{~min}$ at $55^{\circ} \mathrm{C}, 5 \mathrm{~min}$ at $85^{\circ} \mathrm{C}$ and cooling to $4^{\circ} \mathrm{C}$, replicates were pooled together for each of the samples. Resulting cDNA was used as a template in qPCR. Additionally, pooled RNA of all samples was processed without use of Transcriptase to serve as control for DNA contamination (No-RT sample).

Primers (Supplementary Table S1) were designed using Universal Probe Library Assay Design Center (Roche).

Each $10 \mu \mathrm{l}$ reaction consisted of $5 \mu \mathrm{l}$ of $2 \mathrm{x}$ LightCycler 480 Probes Master (Roche), $0.5 \mu \mathrm{l}$ of each of $10 \mathrm{mM}$ primers, $0.1 \mu \mathrm{l}$ of Universal ProbeLibrary (UPL) Probe (Roche) and $2 \mu l$ of template. No template controls (NTC) were prepared using water as template. Each reaction was run in quadruplicates. Reactions were run on a 384-well LightCycler 480 PCR plates and sealed using LightCycler 480 adhesive cover both supplied by Roche. Cycling parameters were $95^{\circ} \mathrm{C}$ for $10 \mathrm{~min}$, followed by 55 cycles

\footnotetext{
${ }^{1}$ www.myassays.com
} 
of $95^{\circ} \mathrm{C}$ for $10 \mathrm{~s}$ and $60^{\circ} \mathrm{C}$ for $45 \mathrm{~s}$. Signal intensity was measured at $72^{\circ} \mathrm{C}$ for $1 \mathrm{~s}$. Crossing point $(\mathrm{Cp})$ values were calculated automatically using instrument software.

All target genes were considered as potential normalization genes and were evaluated according to the criteria defined by GeNorm (Vandesompele et al., 2002). Expression was normalized using geometric means of $2\left(\mathrm{~V}_{2 / 3}=0.128\right)$ highly stable genes GAPDH $(M=0.364)$ and $\operatorname{Tbp}(M=0.348)$. The $2^{-\Delta \Delta C T}$ method (Livak and Schmittgen, 2001) was used to normalize the data. Normalized values were represented in relation to expression in PBS-dosed animals on standard or ADR-159 diet. Statistical analysis, one-way ANOVA with correction for multiple testing, was performed using qbase + software (Hellemans et al., 2007).

\section{SCFA Analysis}

Fecal water was prepared by homogenizing the cecum content ( $150-200 \mathrm{mg}$ ) with $1 \mathrm{ml}$ of acidic MilliQ water (10,000 time diluted 36.5-38\% hydrochloric acid in Milli-Q water) using a vortex mixer for $5 \mathrm{~min}$. The homogenized samples were centrifuged at 15,000 rpm for $5 \mathrm{~min}$ and the supernatants were filtered with $0.22 \mu \mathrm{M}$ filters (Corning). Duplicate aliquots of $270 \mu \mathrm{l}$ of filtrate were mixed with $30 \mu \mathrm{l}$ of $10 \mathrm{mM}$ 2-ethylbutyric acid that was used as internal standard. The samples were homogenized briefly followed by a further centrifugation step of $15,000 \mathrm{rpm}$ for $3 \mathrm{~min}$. Finally, the supernatant was transferred to $250 \mu \mathrm{l}$ inserts (Agilent) placed in amber glass $2 \mathrm{ml} \mathrm{GC}$ vials (Agilent) sealed with silicone/PTFE screw caps (Agilent).

A Varian 3800GV system, fitted with an Agilent DB-FFAP column $(30 \mathrm{ml} \times 0.32 \mathrm{~mm} \mathrm{ID} \times 0.25 \mu \mathrm{m} \mathrm{df})$ and a flame ionization detector with a CP-8400 auto-sampler was used to analyze standards and samples by gas chromatography flame ionization detection (GC-FID). A flow rate of $1.3 \mathrm{ml} / \mathrm{min}$ was used with helium as a carrier gas. An initial oven temperature of $50^{\circ} \mathrm{C}$ was maintained for $30 \mathrm{~s}$, then raised to $140^{\circ} \mathrm{C}$ at $10^{\circ} \mathrm{C} / \mathrm{min}$ and held again for $30 \mathrm{~s}$. Finally, the temperature was increased to $240^{\circ} \mathrm{C}$ at $20^{\circ} \mathrm{C} / \mathrm{min}$, and held for $5 \mathrm{~min}$ (for a total run time of $20 \mathrm{~min}$ ). The temperatures of the detector and the injection port were 300 and $240^{\circ} \mathrm{C}$, respectively. A $10 \mu \mathrm{l}$ syringe (Agilent) installed to a CP-8400 auto-sampler (Varian) was used to perform a split-less injection of $0.2 \mu \mathrm{l}$ for each sample or standard. Peak integration was performed with Varian Star Chromatography Workstation version 6.0 software. To check for any potential carryover vials containing $1800 \mu \mathrm{l}$ of water were run between each sample duplicates as blanks. Standards were included in each run to maintain the calibration.

A 7 point standard curve was generated (SCFA 0.1, 0.5, 1, 2, 4, 8 and $10 \mathrm{mM}$; BCFA $0.01,0.05,0.1,0.2,0.4,0.8$ and $1 \mathrm{mM}$ ) in acidic Milli-Q water with $1 \mathrm{mM}$ internal standard. Results are expressed as mean of two technical replicates (except samples B1, B4, B6, C3, C5, D6, D10, D11) calculated to $\mu \mathrm{M}$ per gram of wet mass. Samples A7 and C7 had a mass too low to process.

\section{Statistical Analysis for Physiological Responses}

Statistical analyses were conducted using SPSS software (IBM Corporation). Data that were normally distributed according to Shapiro-Wilk test or that had homogeneous variances were analyzed using parametric tests, one-way ANOVA or repeated measures ANOVA. When required a post hoc analysis was performed using Bonferroni or Games-Howell correction. Not normally distributed data violating the condition of homogeneity of variances were analyzed using the non-parametric KruskalWallis test. Statistical significance was set at $p<0.05$.

\section{S rRNA Gene Metagenomics DNA Isolation, Amplification, Indexing, Normalization, and Sequencing}

DNA isolation and library preparation were conducted as previously described (Warda et al., 2018). The QIAamp Fast DNA Stool mini kit (Qiagen) was used according to the manufacturers' recommendations to isolate DNA from fecal samples stored until processing at $-80^{\circ} \mathrm{C}$. DNA concentration was measured using a Qubit dsDNA HS Assay Kit and DNA quality was assessed by running a $5 \mu$ l sample on a gel. Phusion Polymerase Master Mix and V3-V4 (Forward 5'-TCGTCGGCAGCGTCAGATGTGTATAAGAGACAGCCTA CGGGNGGCWGCAG-3'; Reverse 5'-GTCTCGTGGGCTCG GAGATGTGTATAAGAGACAGGACTACHVGGGTATCTAAT CC- $3^{\prime}$ ) primers were used to amplify the $\mathrm{V} 3$ and $\mathrm{V} 4$ region of $16 \mathrm{~S}$ rRNA genes $\left(98^{\circ} \mathrm{C} 30 \mathrm{~s} ; 25\right.$ cycles of $98^{\circ} \mathrm{C} 10 \mathrm{~s}, 55^{\circ} \mathrm{C} 15 \mathrm{~s}$, $\left.72^{\circ} \mathrm{C} 20 \mathrm{~s} ; 72^{\circ} \mathrm{C} 5 \mathrm{~min}\right)$. Quality and quantity of the amplicons were checked by Qubit dsDNA HS Assay Kit and by running on a gel. This was followed by amplicon cleanup using Ampure XP magnetic beads. Five microliter of cleaned amplicon was used as a template for Index PCR using Phusion Polymerase Master Mix and Nextera XT Index Kit $\left(95^{\circ} \mathrm{C} 30 \mathrm{~s} ; 8\right.$ cycles of $95^{\circ} \mathrm{C} 30 \mathrm{~s}, 55^{\circ} \mathrm{C}$ $\left.30 \mathrm{~s}, 72^{\circ} \mathrm{C} 30 \mathrm{~s} ; 72^{\circ} \mathrm{C} 5 \mathrm{~min}\right)$. The resulting Indexed amplicons were cleaned using Ampure XP magnetic beads and their quality and quantity were checked by Qubit dsDNA HS Assay Kit and running on gel, respectively. Finally, all samples were normalized to $4 \mathrm{nM}$, followed by pooling $5 \mu \mathrm{l}$ of each sample for Illumina MiSeq sequencing by GTAC (Germany).

\section{S rRNA Gene Data Analysis}

First FastQC was used to examine the quality of raw sequences followed by filtering and trimming using Trimmomatic (Bolger et al., 2014) to ensure only high quality reads were retained for further analysis. Briefly, both forward and reverse reads were subjected to the removal of the first 15 bases while the forward was cropped at 240 bases and the reverse at 225 . Next, we filtered reads using a sliding window (4:20) with the minimum read length set to 200 bases. Subsequently, the DADA2 pipeline (Callahan et al., 2016) was used to process and merge the remaining high quality reads. ChimeraSlayer and the Gold database (Edgar et al., 2011) was used for further chimera filtering of the resulting Ribosomal Sequence Variants (RSVs). Sequences were classified from phylum to genus using the Mothur implementation of the Ribosomal Database Project (RDP) classifier and the RDP database (v11.4) with assignments obtaining a bootstrap value of less than $80 \%$ assigned as the preceding rank and unclassified. SPINGO against the RDP (v11.4) with default parameters (similarity score of 0.05 and a bootstrap cut-off of 0.8) (Allard et al., 2015) was used for species classification. 
All downstream analysis (and microbiome figures) were generated in $\mathrm{R}$ (v3.5.1). The phyloseq package (McMurdie and Holmes, 2013) was used to calculate alpha and beta diversity. Alpha diversity comparisons were performed using a MannWhitney test, while beta diversity was via an Adonis test from the vegan package. The differential abundance of the genera and RSVs was carried out with DESeq2 (Love et al., 2014). Analysis was performed separately for the initial effect of the diet (weeks 0 , 2,3 , and 4 ) and the effect of the dosing (before dosing/week 4, 8, 12 , and 18 days post dosing).

\section{Virome Analysis}

\section{Fecal Virus-Like Particles (VLPs) Nucleic Acid Extraction}

Pooled fecal samples of $0.2-1.5 \mathrm{~g}$ per cage were stored at $-80^{\circ} \mathrm{C}$ until processing according to a previously published method (Shkoporov et al., 2018). In brief, feces were resuspended in $10 \mathrm{ml}$ of SM buffer and vortexed for $5 \mathrm{~min}$. Following $5 \mathrm{~min}$ incubation on ice tubes were centrifuged at $5000 \mathrm{rpm}$ in a swing bucket rotor for $10 \mathrm{~min}$ at $4^{\circ} \mathrm{C}$. Supernatants were transferred to new tubes, and centrifugation was repeated once again. A 0.45 $\mu \mathrm{m}$ pore PES syringe-mounted membrane filters were used to filter supernatant; this was repeated once. The filtrates were first supplemented with $5 \mathrm{M} \mathrm{NaCl}$ solution to a final concentration of $0.5 \mathrm{M}$, next Polyethylene glycol (PEG-8000) powder was added to a final concentration of $10 \% \mathrm{w} / \mathrm{v}$. Following the resuspension, samples were kept for $16 \mathrm{~h}$ at $4^{\circ} \mathrm{C}$.

The precipitate was collected by centrifugation of samples at $5000 \mathrm{rpm}$ for $20 \mathrm{~min}$ at $4^{\circ} \mathrm{C}$. The supernatant was discarded, and any residual supernatant was removed by 5 min incubation of the tubes in an inverted position on paper towels. Pellets were then resuspended in $400 \mu \mathrm{l}$ of SM buffer, supplemented with $400 \mu \mathrm{l}$ of chloroform and extracted by gentle shaking. A desktop centrifuge (2500 $\mathrm{g}$ for $5 \mathrm{~min}$ ) was used to facilitate phase separation. The aqueous phase $(\sim 360 \mu \mathrm{l})$ was transferred into fresh tubes and mixed with $40 \mu \mathrm{l}$ of a solution of $10 \mathrm{mM} \mathrm{CaCl} 2$ and $50 \mathrm{mM} \mathrm{MgCl}_{2}$. DNA/RNA digestion was carried out at $37^{\circ} \mathrm{C}$ for $1 \mathrm{~h}$ by addition of $16 \mathrm{U}$ of TURBO DNase (Ambion/Thermo Fisher Scientific) and $20 \mathrm{U}$ of RNase I (Thermo Fisher Scientific). Digestion enzymes were heat inactivated at $70^{\circ} \mathrm{C}$ for $10 \mathrm{~min} .2 \mu \mathrm{l}$ of Proteinase $\mathrm{K}$ (Qiagen) and $20 \mu \mathrm{l}$ of $10 \%$ SDS were then added to the tubes, and incubation was continued for $20 \mathrm{~min}$ at $56^{\circ} \mathrm{C} .100$ $\mu \mathrm{l}$ of Phage Lysis Buffer (4.5 M guanidinium isothiocyanate, $44 \mathrm{mM}$ sodium citrate $\mathrm{pH} 7.0,0.88 \%$ sarkosyl, $0.72 \% \quad 2$ mercaptoethanol) was added and kept at $65^{\circ} \mathrm{C}$ for $10 \mathrm{~min}$ to lyse the viral particles. Finally, lysates were extracted by gentle vortexing with equal volume of Phenol/Chloroform/Isoamyl Alcohol 25:24:1 (Fisher Scientific) followed by centrifugation at $8,000 \times \mathrm{g}$ for $5 \mathrm{~min}$ at room temperature. The phenol/chloroform extraction step was repeated. DNeasy Blood \& Tissue Kit (Qiagen) was used to purify the resulting aqueous phase according to manufacturer's instruction, with a final elution volume of $50 \mu \mathrm{l}$.

As a negative control, the procedure was performed with no fecal samples.

\section{Shotgun Sequencing of Fecal VLP Nucleic Acids}

Reverse transcription, multiple displacement amplification (MDA) and library preparation were conducted according to a previously published method (Shkoporov et al., 2018). SuperScript IV Reverse Transcriptase (RT) kit (Invitrogen/ThermoFisher Scientific) was used according to the manufacturer's random hexamer primer protocol. More specifically eleven microliters of fecal VLP nucleic acid sample regardless of concentration was used for the reverse transcription reaction. One microliter of reverse-transcribed nucleic acids was then amplified using MDA technology with Illustra GenomiPhi V2 kit (GE Healthcare). The latter step was done in triplicate for each sample. The remainder of RT products $(17 \mu \mathrm{l})$ and the products from all three MDA reactions were pooled together and subjected to additional round of purification using DNeasy Blood \& Tissue Kit.

Qubit dsDNA HS Assay Kit (Invitrogen/Thermo Fisher Scientific) was used to quantify the amplified DNA. Nextera XT Nano DNA Library Preparation Kit (Illumina) was used for the random shotgun library preparation and bead-based normalization following the standard manufacturer's protocol. Ready-to-load libraries were sequenced using a proprietary modified protocol using $2 \times 300$ bp paired-end chemistry on an Illumina MiSeq platform (Illumina, San Diego, CA, United States) at GATC Biotech AG, Germany.

\section{Virome Data Analysis}

Raw sequence quality was accessed using FASTQC while reads were filtered using the following parameters; HEADCROP:10, CROP: 125 and 120 bp for forward and reverse respectively; SLIDINGWINDOW: $4: 20$ and a MINLEN of 50 bp. Read assembly of the retained high quality reads was carried out per sample using SPAdes in metagenomic mode (Nurk et al., 2017). Assemblies were pooled and all contigs greater than 1 $\mathrm{kb}$ were retained. Redundancy was removed with $90 \%$ identity over $90 \%$ of the length (of the shorter) retaining the longest contig in each case. Using a set of criteria, bacterial contamination was removed thereby retaining only viral genomes or partial genomes. Briefly, a contig must meet at least one of the following; (1) alignment to an in-house crAssphage database (Guerin et al., 2018) (threshold: 1e-10), (2) a minimum of 2 pVogs with at least 3 per $1 \mathrm{~kb}$ (Grazziotin et al., 2017), (3) VirSorter positive (Roux et al., 2015), (4) circular, (5) greater than 3 $\mathrm{kb}$ with no hits to the NT database (January 19) (threshold: 1e-10), (6) hits to viral RefSeq database (v.89) (threshold: 1e10 ), and finally, (7) less than 3 ribosomal proteins as predicted using the COG database (Tatusov et al., 2000). Post-filtering, high quality reads were aligned to the reference set of viral contigs $(n=5,638)$ using bowtie2. SAMtools was employed to generate a count table and a $75 \%$ breadth of coverage filter was utilized to prevent false positives from spurious alignments to repeat regions. Any counts which did not meet the $75 \%$ threshold were set to 0 . This resulted in a final set of 5,016 viral contigs.

Alpha and beta diversity analysis were performed separately for the initial effect of the diet (weeks 0,2 , and 4) and the effect of the dosing (before dosing/week $4,8,12$, and 18 days post-dosing). 


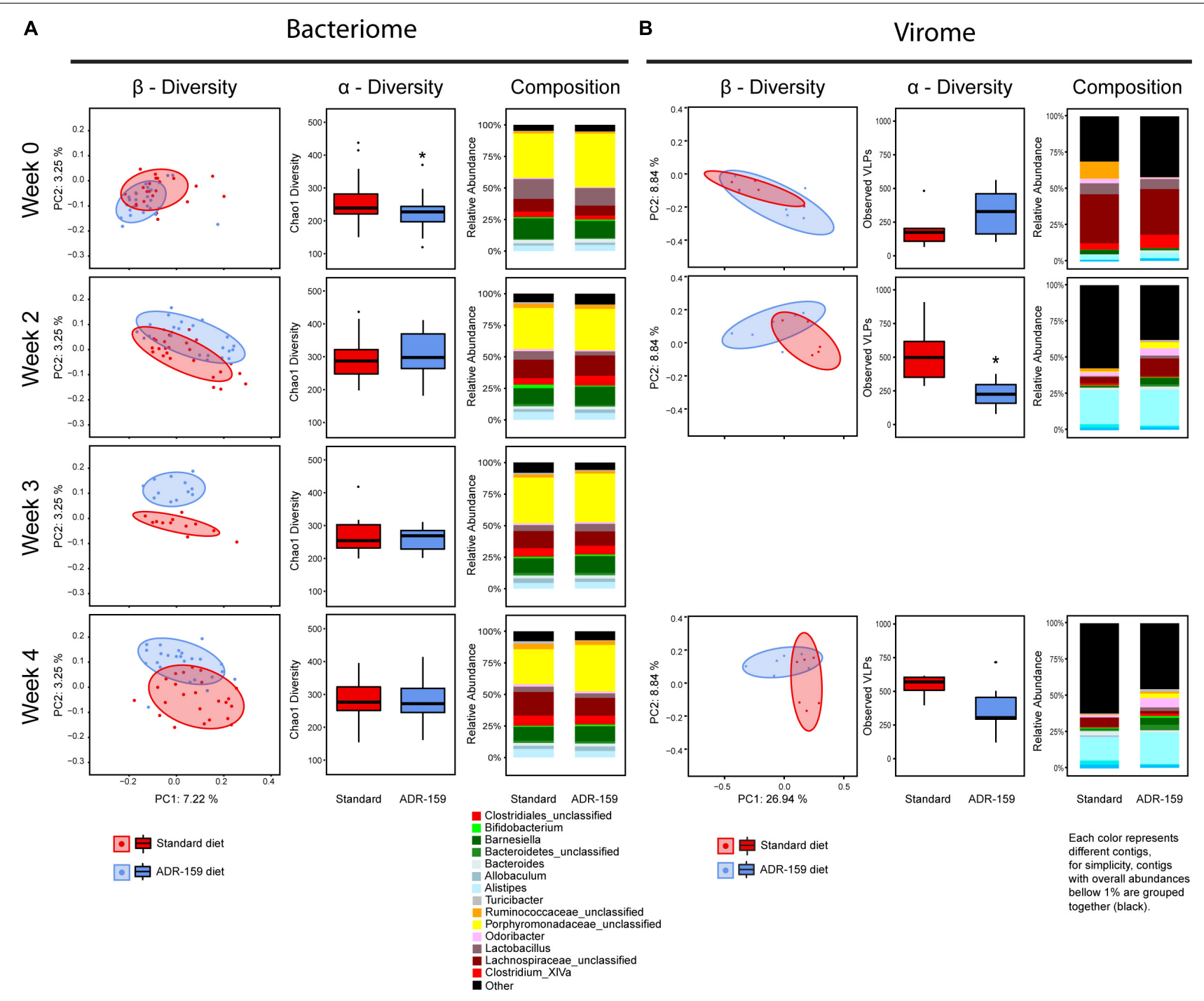

FIGURE 2 | Microbiome analysis before (week 0) and during (weeks 2, 3, and 4) the diet intervention with standard (red) and ADR-159 (blue) diet. (A) Bacteriome. 24 animals are represented per group at weeks 0,2 , and 4 , while only 12 animals per group in week 3 . Left: PCoA plots of microbiome composition using Jaccard distances. Each dot represents individual animal at each given time point. Ellipses represent the confidence interval of every group at $75 \%$. Middle: Chao1 index, * indicates significant difference. Right: mean abundance at genus level. For simplicity, genera with abundances below $1 \%$ were grouped together. (B) Virome. Each group represents 6 cages, each of 4 animals. Left: PCoA plots of virome composition using the Spearman distances. Each dot represents a cage with 4 individual animals at each given time point. Ellipses represent the confidence interval of every group at $75 \%$. Middle: observed number of viral contigs, ${ }^{*}$ indicates significant difference. Right: mean abundance of viral contigs. Each color represents different contig, for simplicity, contigs with overall abundances below $1 \%$ were grouped together (black).

\section{RESULTS}

\section{ADR-159 Diet Subtly Modifies the Murine Microbiome}

Bacteroidetes and Firmicutes were the dominant phyla in the microbiome of both standard and ADR-159 fed animals (data not shown), with no clear difference between groups throughout the experiment. At the genus level, the microbiome composition of both cohorts was more diverse, with a high contribution of unclassified Porphyromonadaceae (approximately 45\% in each of the samples) (Figure $\mathbf{2 A}$ and Supplementary Figure S2).
This absence of radical differences in microbiome composition between the two groups of animals indicates that extended consumption of ADR-159 did not result in a preeminent disruption of the microbiome of healthy animals, but did cause subtle statistically significant modifications over the initial 4 -week period (Figure 2A) (ADONIS; $p=0.002, p=0.001$, $p=0.002, p=0.001)$. Still, over $10 \%$ of variability shown on Figure 2A could be explained by combination of PC1 and PC2 axes. More specifically, in ADR-159 fed animals we observed a stable reduction of Turicibacter, Clostridium sensu strict, and Dorea (Table 1). To investigate subtle changes in microbiome composition we also performed analysis at the Ribosomal 
Sequence Variants (RSV) level. Only 22 RSVs were differentially abundant, supporting the initial observations. Four of those RSVs could be assigned to species level (Bifidobacterium pseudolongum, Clostridium disporicum, Clostridium ruminantium, Turicibacter sanguinis, Supplementary Table S2).

The compositional analysis described above ( $\beta$-diversity) illustrates the degree of difference in the microbial composition of animals on the different diets. The $\alpha$-diversity, which is presented below, describes the number of different species detected in animals on a given diet.

The $\alpha$-diversity of the microbiome, evaluated using both Chaol (Figure 2A) and Shannon indexes (data not shown), did not undergo consistent changes during the trial. Before diet differentiation, animals assigned to the ADR-159 group had a slightly reduced $\alpha$-diversity compared to the standard diet group, nevertheless this difference became insignificant by week 2 of the trial. Similarly, the microbiome of animals at week 0 differed slightly between animals randomly assigned to standard and ADR-159 fed groups. Initially (at week 0) animals in the ADR159 group had lower abundance of Mucispirillum compared to the standard-fed group (Table 1), this difference was not observed over the following weeks, suggesting that the initial differences were due to chance. Other studies have also reported initial differences in limited numbers of taxa/OTUs between groups (Holder et al., 2019). Although we focus on the effect of the diet at the given time point, it is important to note that the microbiome of animals on both diets exhibited compositional changes and changes in $\beta$-diversity during the course of the experiment (Supplementary Figure S2) indicating the dynamic nature of the microbiome.

\section{Virome Analysis Confirms Subtle Nature of Microbiome Changes in ADR-159 Fed Animals}

Virome analysis was performed per cage rather than per individual. Prior to diet diversification, virome $\beta$-diversity was comparable between the standard and ADR-159 fed animals (ADONIS, $p=0.4645$ ). Over time, the separation between the viromes of the two groups reached significance at week 4 (ADONIS, $p=0.04795$ ). A considerably higher percentage of variability was explained by virome PC1 and PC2, 26.94 and 8.84\%, respectively (Figure 2B) compared to $16 \mathrm{~S}$. Virome $\alpha$-diversity in standard fed animals increased after diet diversification $(p=0.0185)$, while in ADR-159 fed animals it remained stable with approximately 250 observed viral contigs. After 2 weeks virome $\alpha$-diversity was significantly higher in standard fed animals compared to those receiving ADR-159 ( $p=0.01515)$ (Figure 2 and Supplementary Table S4).

The viral contig composition dramatically changed during the initial 2 weeks independent of the diet, indicating that despite acclimatization animals on both standard and ADR-159 diets were still undergoing change, probably at a level under the discriminatory power of $16 \mathrm{~S} \mathrm{rDNA}$ analysis (Figure 2B). As many as 56 viral contigs were differently abundant in at least two time points, while 94,279 , and 127 viral contigs were differentially abundant at single time point (weeks 0,2 , and 4, respectively; data not shown). A higher compositional diversity was observed between virome samples (Supplementary Figure S3) compared to individual $16 \mathrm{~S}$ samples.

Nevertheless, the virome of animals in both groups underwent similar changes, corroborating a lack of major disruption of the microbiome in the ADR-159 fed animals and supporting a more subtle change in less abundant taxa and at sub-OTU level.

\section{Effect of ADR-159 Diet Modification of Microbiome on Citrobacter Infection}

At week 4, half of the animals on each diet were orally dosed with Citrobacter while the other half were dosed with PBS to serve as a control. All mice continued on the same diets for the remainder of the experiment. Despite the initiation of an intensive animal handling phase of the trial, the microbiome of ADR-159 fed animals maintained the reduction of Turicibacter and Clostridium sensu stricto as well as an increase of unclassified Prevotellaceae that began at week 4 (Table 2). Additional stable changes (two consecutive time points) included a reduction in unclassified Bacteroidetes and Clostridium XI in ADR-159 fed animals (Table 2). These changes may reflect not only response to extended exposure to the diet but rather a combination of diet and animal handling. Still, over $10 \%$ of bacteriome variability following dosing could be explained by the combination of PC1 and PC2 axes (Figure 3A).

Overall, prior to dosing animals with Citrobacter or PBS, the microbiome of the animals differed ( $\beta$-diversity and composition) as a result of the 4 -week periods of standard or ADR-159 diet (Figure 2). Throughout the infection process ( 8-, $12-$, and 18-days post-initial dosing) this clear division between the microbiomes of standard and ADR-159 fed animals based on $\beta$-diversity and composition was maintained (Figure 3A). Citrobacter infection did not cause a major disruption to the microbiome (Figure 3A and Supplementary Figure S2), but Citrobacter was detected in the microbiome of a majority of Citrobacter dosed animals at levels of approximately $0.2 \%$. In animals on both diets Citrobacter infection coincided with a reduction in Bacteroides, while the impact of dosing on other genera depended on the diet (Table 2 and Supplementary Table S3). Citrobacter infected animals on standard diet had increased levels of Citrobacter and Vampirovibrio, and reduced levels of Anaeroplasma, unclassified Bacteroidetes and Flavonifactor (Table 2 and Supplementary Table S3) as compared to healthy controls. At the same time, Citrobacter infected animals on the ADR-159 diet had increased levels of Allobaculum and reduced levels of Alistipes and unclassified Prevotellaceae, as compared to uninfected controls.

There was no major effect of Citrobacter dosing on $\alpha$-diversity as evaluated by both Chaol (Figure 3A) and Shannon indexes. Before infection animals assigned to the ADR-159/Citrobacter group had reduced Chaol diversity compared to ADR-159/PBS group but this difference was not maintained post-dosing.

\section{Impact of ADR-159 on Virome of Mice Following Citrobacter Infection}

Following dosing with $\mathrm{PBS}$ or $C$. rodentium, virome analysis was continued per cage, with 3 cages per group (Figure 3B). Following the dosing, numbers of observed viral contigs for 
TABLE 1 | Genera differently abundant during 4 weeks of ADR-159 feeding compared to animals fed a standard diet.

\begin{tabular}{|c|c|c|c|c|c|c|c|c|c|c|c|c|c|}
\hline \multirow[t]{2}{*}{ Genus } & \multicolumn{3}{|c|}{ Week 0} & \multicolumn{3}{|c|}{ Week 2} & \multicolumn{3}{|c|}{ Week 3} & \multicolumn{3}{|c|}{ Week 4} & \multirow{2}{*}{$\begin{array}{l}\text { Effect in ADR-159 } \\
\text { diet group }\end{array}$} \\
\hline & $\begin{array}{l}\text { Mean control } \\
\operatorname{diet}(\mathrm{AB})\end{array}$ & $\begin{array}{l}\text { Mean } \\
\text { ADR-159 } \\
\text { diet (CD) }\end{array}$ & $\begin{array}{l}p \text {-value } \\
\text { adjusted }\end{array}$ & $\begin{array}{l}\text { Mean control } \\
\operatorname{diet}(A B)\end{array}$ & $\begin{array}{l}\text { Mean } \\
\text { ADR-159 } \\
\text { diet (CD) }\end{array}$ & $\begin{array}{l}p \text {-value } \\
\text { adjusted }\end{array}$ & $\begin{array}{l}\text { Mean control } \\
\operatorname{diet}(\mathrm{AB})\end{array}$ & $\begin{array}{l}\text { Mean } \\
\text { ADR-159 } \\
\text { diet (CD) }\end{array}$ & $\begin{array}{l}p \text {-value } \\
\text { adjusted }\end{array}$ & $\begin{array}{l}\text { Mean control } \\
\operatorname{diet}(A B)\end{array}$ & $\begin{array}{l}\text { Mean } \\
\text { ADR-159 } \\
\text { diet (CD) }\end{array}$ & $\begin{array}{l}p \text {-value } \\
\text { adjusted }\end{array}$ & \\
\hline Bifidobacterium & & & & 2.77E-02 & 7.54E-03 & 4.71E-03 & & & & & & & Temporary $\downarrow$ \\
\hline Clostridiales unclassified & & & & 1.87E-02 & 3.29E-02 & 4.01E-02 & & & & & & & Temporary $\uparrow$ \\
\hline Clostridium sensu stricto & & & & 3.35E-03 & $2.51 \mathrm{E}-04$ & 1.46E-05 & 4.33E-03 & 1.85E-05 & 1.30E-02 & 6.03E-03 & 5.54E-04 & 5.04E-06 & $\downarrow$ \\
\hline Clostridium XI & & & & $1.53 \mathrm{E}-03$ & 3.20E-05 & 4.95E-02 & & & & & & & Temporary $\downarrow$ \\
\hline Clostridium XIVb & & & & & & & & & & 2.16E-03 & $9.13 \mathrm{E}-04$ & 6.69E-03 & Temporary $\downarrow$ \\
\hline $\begin{array}{l}\text { Desulfohalobiaceae } \\
\text { unclassified }\end{array}$ & & & & & & & 7.20E-03 & 1.89E-03 & 3.12E-02 & & & & Temporary $\downarrow$ \\
\hline Dorea & & & & 1.73E-03 & 7.19E-04 & 2.56E-02 & & & & 2.69E-03 & 1.17E-03 & $1.01 \mathrm{E}-02$ & $\downarrow$ \\
\hline $\begin{array}{l}\text { Enterobacteriaceae } \\
\text { unclassified }\end{array}$ & & & & 1.03E-04 & $6.59 \mathrm{E}-04$ & 4.95E-02 & & & & & & & Temporary $\uparrow$ \\
\hline Eubacterium & & & & & & & & & & $9.03 \mathrm{E}-05$ & 2.97E-04 & 4.00E-02 & Temporary $\uparrow$ \\
\hline Lachnospira & & & & & & & & & & $1.13 \mathrm{E}-03$ & $2.32 \mathrm{E}-04$ & 3.37E-04 & Temporary $\downarrow$ \\
\hline Lactobacillus & & & & 6.79E-02 & 3.16E-02 & 2.56E-02 & & & & & & & Temporary $\downarrow$ \\
\hline Mucispirillum & 2.57E-03 & $3.18 \mathrm{E}-04$ & $9.63 \mathrm{E}-03$ & & & & & & & & & & $\begin{array}{l}\text { Recovery from } \\
\text { initially lower level }\end{array}$ \\
\hline $\begin{array}{l}\text { Porphyromonadaceae } \\
\text { unclassified }\end{array}$ & & & & & & & & & & 2.77E-01 & 3.66E-01 & 6.69E-03 & Temporary $\uparrow$ \\
\hline Prevotellaceae unclassified & & & & & & & & & & 4.99E-03 & 8.09E-03 & $1.01 \mathrm{E}-02$ & Temporary $\uparrow$ \\
\hline Turicibacter & & & & 1.13E-02 & $2.66 \mathrm{E}-03$ & $4.29 \mathrm{E}-04$ & & & & $2.08 \mathrm{E}-02$ & $5.04 \mathrm{E}-03$ & 5.04E-06 & $\downarrow$ \\
\hline
\end{tabular}


TABLE 2 | Genera differently abundant before and 8, 12, and 18 days post-initial dosing with PBS (A, C) and Citrobacter (B, D) of standard (A, B), and ADR-159 (C, D) fed animals.

\begin{tabular}{|c|c|c|c|c|c|c|c|c|c|c|c|c|c|c|c|c|}
\hline \multirow[t]{2}{*}{ Difference } & \multirow[t]{2}{*}{$\begin{array}{l}\text { Condition } \\
1\end{array}$} & \multirow[t]{2}{*}{$\begin{array}{l}\text { Condition } \\
2\end{array}$} & \multirow[t]{2}{*}{ Genus } & \multicolumn{3}{|c|}{ Before dosing (week 4) } & \multicolumn{3}{|c|}{8 days post-dosing } & \multicolumn{3}{|c|}{12 days post-dosing } & \multicolumn{3}{|c|}{$\begin{array}{l}18 \text { days post-dosing } \\
\text { (sacrifice) }\end{array}$} & \multirow[t]{2}{*}{ Effect } \\
\hline & & & & Mean 1 & Mean 2 & $\begin{array}{l}\text { p-value } \\
\text { adjusted }\end{array}$ & Mean 1 & Mean 2 & $\begin{array}{l}\text { p-value } \\
\text { adjusted }\end{array}$ & Mean 1 & Mean 2 & $\begin{array}{l}\text { p-value } \\
\text { adjusted }\end{array}$ & Mean 1 & Mean 2 & $\begin{array}{l}\text { p-value } \\
\text { adjusted }\end{array}$ & \\
\hline \multirow[t]{15}{*}{$\begin{array}{l}\text { Difference in } \\
\text { diet - no } \\
\text { infection }\end{array}$} & $\begin{array}{l}\text { Standard } \\
\text { diet/ PBS } \\
\text { dosing }\end{array}$ & $\begin{array}{l}\text { ADR-159 } \\
\text { diet/ PBS } \\
\text { dosing }\end{array}$ & Allobaculum & & & & 6.37E-02 & $1.08 \mathrm{E}-02$ & $2.79 \mathrm{E}-03$ & & & & & & & $\begin{array}{l}\text { Temporary } \downarrow \text { in } \\
\text { ADR-159 }\end{array}$ \\
\hline & & & Anaeroplasma & & & & 6.29E-04 & 3.96E-05 & 3.32E-02 & & & & & & & \\
\hline & & & $\begin{array}{l}\text { Bacteroidales } \\
\text { unclassified }\end{array}$ & & & & & & & 1.77E-03 & $3.18 \mathrm{E}-03$ & 1.21E-02 & & & & $\begin{array}{l}\text { Temporary } \uparrow \text { in } \\
\text { ADR-159 }\end{array}$ \\
\hline & & & $\begin{array}{l}\text { Bacteroidetes } \\
\text { unclassified }\end{array}$ & & & & & & & 2.93E-02 & 1.45E-02 & $1.82 \mathrm{E}-03$ & 2.84E-02 & $1.81 \mathrm{E}-02$ & 1.10E-02 & $\downarrow$ in ADR-159 \\
\hline & & & Bifidobacterium $^{*}$ & & & & 2.83E-02 & 4.00E-03 & 1.44E-03 & & & & & & & \\
\hline & & & $\begin{array}{l}\text { Candidatus } \\
\text { Saccharibacteria } \\
\text { unclassified }\end{array}$ & & & & & & & 1.80E-03 & 3.97E-04 & 1.95E-03 & & & & $\begin{array}{l}\text { Temporary } \downarrow \text { in } \\
\text { ADR-159 }\end{array}$ \\
\hline & & & Clostridia unclassified & & & & & & & 7.34E-04 & $1.50 \mathrm{E}-04$ & 4.79E-02 & & & & \\
\hline & & & $\begin{array}{l}\text { Clostridium sensu } \\
\text { stricto* }^{*}\end{array}$ & $6.96 \mathrm{E}-03$ & $3.65 \mathrm{E}-04$ & 1.06E-02 & $5.14 \mathrm{E}-03$ & 7.34E-04 & $1.13 \mathrm{E}-02$ & $6.43 \mathrm{E}-03$ & $3.34 \mathrm{E}-04$ & $1.95 \mathrm{E}-03$ & 5.32E-03 & 8.03E-04 & 8.07E-03 & $\downarrow$ in ADR-159 \\
\hline & & & Clostridium $\mathrm{XI}^{*}$ & & & & 1.37E-03 & $0.00 \mathrm{E}+00$ & $3.31 \mathrm{E}-02$ & $1.21 \mathrm{E}-03$ & $0.00 \mathrm{E}+00$ & $2.90 \mathrm{E}-03$ & 1.14E-03 & $1.92 \mathrm{E}-04$ & 1.10E-02 & \\
\hline & & & $\begin{array}{l}\text { Deltaproteobacteria } \\
\text { unclassified }\end{array}$ & & & & & & & $5.77 \mathrm{E}-04$ & 1.33E-04 & $3.43 \mathrm{E}-02$ & & & & $\begin{array}{l}\text { Temporary } \downarrow \text { in } \\
\text { ADR-159 }\end{array}$ \\
\hline & & & Flavonifractor & & & & & & & $1.41 \mathrm{E}-02$ & 5.05E-03 & $1.82 \mathrm{E}-03$ & & & & \\
\hline & & & $\begin{array}{l}\text { Porphyromonadaceae } \\
\text { unclassified* }^{*}\end{array}$ & $2.53 E-01$ & 3.62E-01 & 4.40E-02 & & & & & & & & & & $\uparrow$ in ADR-159 \\
\hline & & & $\begin{array}{l}\text { Prevotellaceae } \\
\text { unclassified }^{*}\end{array}$ & & & & & & & $6.16 \mathrm{E}-03$ & 1.46E-02 & $1.76 \mathrm{E}-03$ & & & & \\
\hline & & & Ruminococcus & & & & & & & & & & $1.38 \mathrm{E}-02$ & 5.90E-03 & 2.03E-02 & $\begin{array}{l}\text { Temporary } \downarrow \text { in } \\
\text { ADR-159 }\end{array}$ \\
\hline & & & Turicibacter ${ }^{\star}$ & 2.00E-02 & 5.02E-03 & 1.06E-02 & $2.18 \mathrm{E}-02$ & 3.22E-03 & 1.44E-03 & $3.46 \mathrm{E}-02$ & $6.35 \mathrm{E}-03$ & $2.42 \mathrm{E}-03$ & 2.89E-02 & $7.28 \mathrm{E}-03$ & 8.65E-03 & $\downarrow$ in ADR-159 \\
\hline \multirow[t]{4}{*}{$\begin{array}{l}\text { Same diet } \\
\text { (ADR-159) - } \\
\text { difference in } \\
\text { infection }\end{array}$} & $\begin{array}{l}\text { ADR-159 } \\
\text { diet/PBS } \\
\text { dosing }\end{array}$ & $\begin{array}{l}\text { ADR-159 } \\
\text { diet/ } \\
\text { Citrobacter } \\
\text { dosing }\end{array}$ & Alistipes & & & & & & & & & & 6.06E-02 & 3.22E-02 & 8.51E-03 & $\begin{array}{l}\text { Temporary } \downarrow \text { in } \\
\text { Citrobacter }\end{array}$ \\
\hline & & & Allobaculum & & & & $1.08 \mathrm{E}-02$ & 4.98E-02 & 2.82E-03 & & & & & & & $\begin{array}{l}\text { Temporary } \uparrow \text { in } \\
\text { Citrobacter }\end{array}$ \\
\hline & & & Bacteroides & & & & $3.72 \mathrm{E}-02$ & 1.65E-02 & 1.41E-02 & 3.89E-02 & 1.21E-02 & $1.41 \mathrm{E}-03$ & & & & $\downarrow$ in Citrobacter \\
\hline & & & $\begin{array}{l}\text { Prevotellaceae } \\
\text { unclassified }\end{array}$ & & & & & & & 1.46E-02 & 5.89E-03 & 1.41E-03 & & & & $\begin{array}{l}\text { Temporary } \downarrow \text { in } \\
\text { Citrobacter }\end{array}$ \\
\hline $\begin{array}{l}\text { Same diet } \\
\text { (standard) - } \\
\text { difference in } \\
\text { infection }\end{array}$ & $\begin{array}{l}\text { Standard } \\
\text { diet/PBS } \\
\text { dosing }\end{array}$ & $\begin{array}{l}\text { Standard } \\
\text { diet/ } \\
\text { Citrobacter } \\
\text { dosing }\end{array}$ & Anaeroplasma & & & & & & & $1.02 \mathrm{E}-03$ & 1.02E-05 & 2.93E-02 & & & & $\begin{array}{l}\text { Temporary } \downarrow \text { in } \\
\text { Citrobacter }\end{array}$ \\
\hline
\end{tabular}




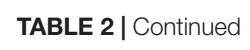

(n)

\begin{tabular}{|c|c|c|c|c|c|c|c|c|c|c|c|}
\hline Mean 1 & Mean 2 & $\begin{array}{l}\text { p-value } \\
\text { adjusted }\end{array}$ & Mean 1 & Mean 2 & $\begin{array}{l}\text { p-value } \\
\text { adjusted }\end{array}$ & Mean 1 & Mean 2 & $\begin{array}{l}\text { p-value } \\
\text { adjusted }\end{array}$ & Mean 1 & Mean 2 & $\begin{array}{l}\mathrm{p} \text {-value } \\
\text { adjusted }\end{array}$ \\
\hline
\end{tabular}

Bacteroides

Bacteroidetes

unclassified

$2.68 \mathrm{E}-02$ 1.00E-02 2.90E-04

Citrobacter

Flavonifractor

0.00E+00 6.32E-03 1.21E-02

Temporary $\uparrow$ in

$1.41 \mathrm{E}-02 \quad 6.85 \mathrm{E}-03 \quad 1.20 \mathrm{E}-02$

Temporary $\downarrow$ in

Vampirovibrio

Difference Standard diet/ ADR-159 diet/ Akkermansia

in diet - all Citrobacter Citrobacter

infected dosing dosing

\author{
Alistipes \\ Bacteroidales \\ unclassified \\ 6.74E-02 4.46E-02 2.64E-02$$
\text { stricto* }
$$ \\ Clostridium $\mathrm{XI}^{*}$ \\ Clostridium XIVb* 1.97E-03 4.86E-04 2.52E-02 \\ Dorea* \\ Flavonifractor \\ Lachnospira* $\quad 1.00 \mathrm{E}-03 \quad 1.83 \mathrm{E}-04 \quad 2.52 \mathrm{E}-02$ \\ Proteobacteria \\ unclassified \\ Ruminococcaceae \\ unclassified

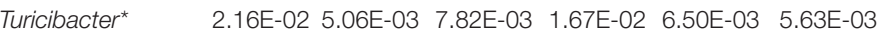 \\ Vampirovibrio
}

$2.71 \mathrm{E}-04 \quad 1.51 \mathrm{E}-03 \quad 6.68 \mathrm{E}-03$

Citrobacter

Temporary $\uparrow$ in Citrobacter

4.88E-03 2.84E-02 4.87E-02 Temporary $\uparrow$ in ADR-159

$1.51 \mathrm{E}-03 \quad 2.99 \mathrm{E}-04 \quad 2.15 \mathrm{E}-02$

6.88E-02 4.11E-02 3.36E-02 5.92E-02 3.22E-02 1.56E-02 $\downarrow$ in ADR-159

$1.40 \mathrm{E}-03 \quad 3.92 \mathrm{E}-03 \quad 2.15 \mathrm{E}-02 \quad$ Temporary $\uparrow$ in

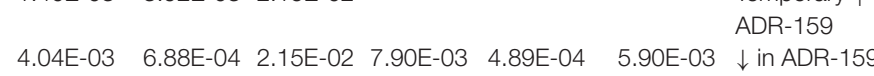

$1.51 \mathrm{E}-03 \quad 0.00 \mathrm{E}+00 \quad 2.10 \mathrm{E}-03 \quad$ Temporary $\downarrow$ in ADR-159

2.80E-03 8.56E-04 4.87E-02 8.95E-03 4.42E-03 4.87E-02

4.08E-03 1.33E-03 4.73E-02

4.10E-02 2.18E-02 4.07E-02

2.29E-02 6.85E-03 1.56E-02 $\downarrow$ in ADR-159

Temporary $\downarrow$ in ADR-159

*Indicated taxa significantly different at one of the initial 4 weeks of experiment. 


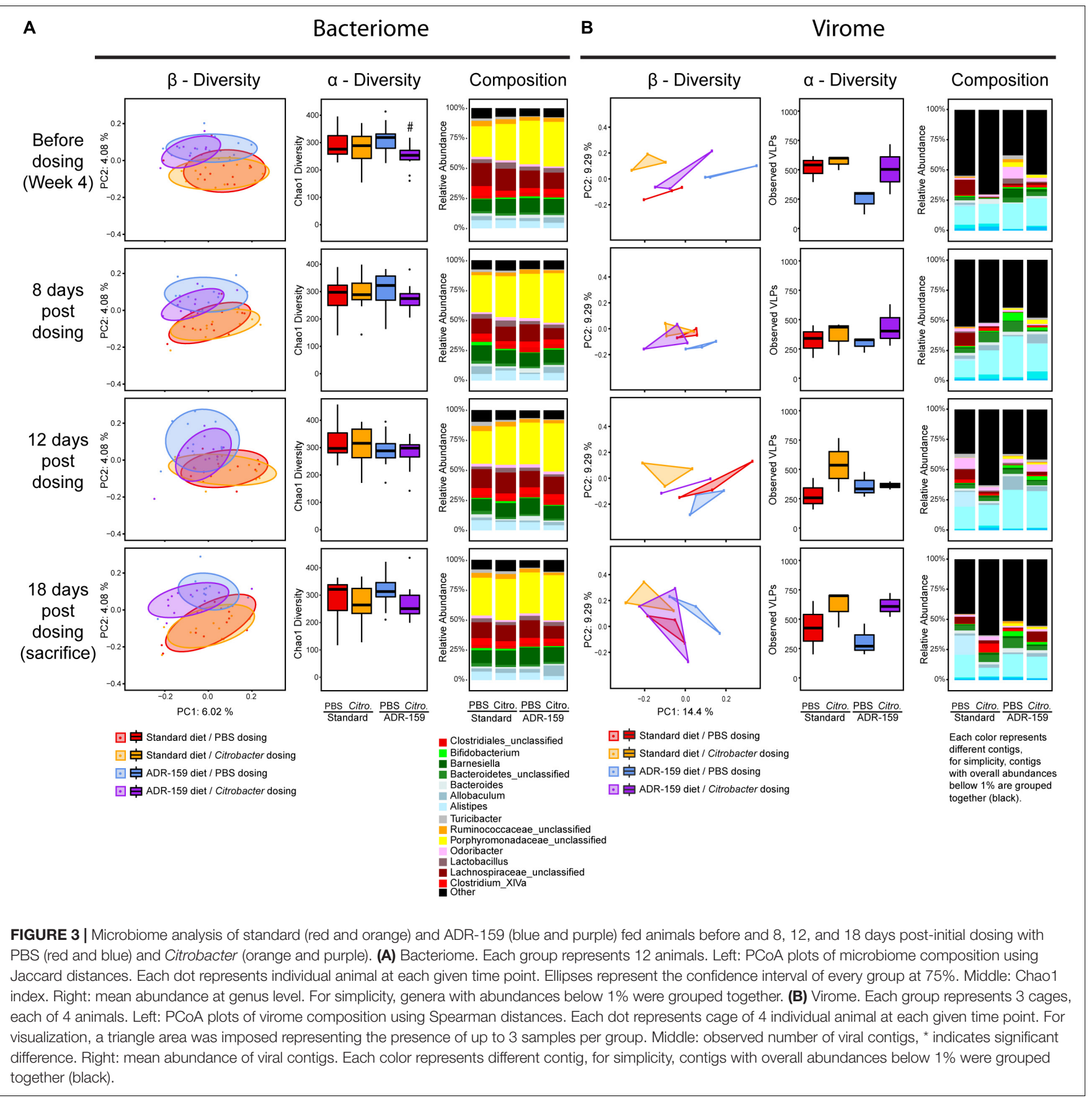

healthy standard fed animals continued to fluctuate, as it did during the initial 4 weeks of the experiment (Figure 3B). At the same time, numbers of observed viral contigs for PBSdosed ADR-159 fed animals remained stable. Overall, higher numbers of viral contigs were observed in animals dosed with Citrobacter compared to healthy controls, however, statistical significance was limited by low sample numbers as virome analysis was done per cage, resulting in only three samples per group (Supplementary Table S5).

Virome composition revealed higher diversity when compared to $16 \mathrm{~S}$ data, which may be attributed to the pooled nature of the collected samples and the fact that low abundance contigs (less than $1 \%$ ) represent approximately $50 \%$ of the total (Figure 3B). None of the viral contigs could be associated with Citrobacter infecting phages or Citrobacter hosts.

\section{ADR-159 Diet Has No Effect on Body Weight}

There was no difference in initial body weight of animals assigned to receive standard or ADR-159 diet (Mann-Whitney $U$-test, $p=0.317)$. While the body weight of all animals changed over time [repeated measures ANOVA, Greenhouse-Geisser; 


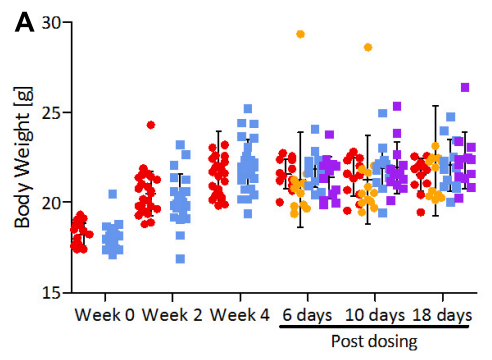

- Standard diet / PBS
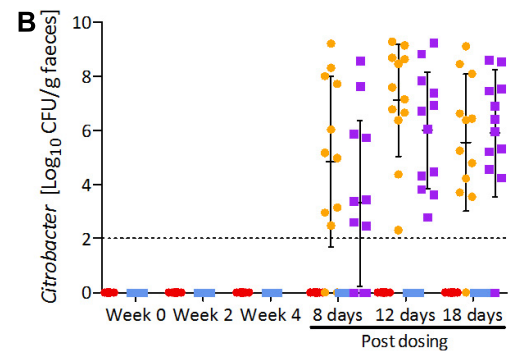

- ADR-159 diet / PBS

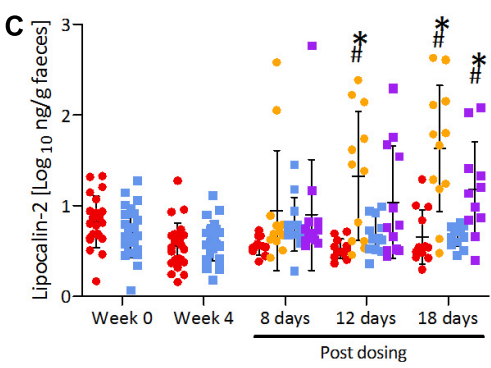

- ADR-159 diet / Citrobacter

FIGURE 4 | Measurements for standard (circle) and ADR-159 (square) fed animals dosed with C. rodentium (orange, purple) or PBS (red, blue) before start of the diet, after 4 weeks of the diet (before dosing) and up to 18 days post-dosing (sacrifice). Error bars represent SD. (A) Body weight. (B) Average C. rodentium levels shed before and after initial dosing. (C) Fecal lipocalin-2 (LCN2) levels. * Indicates significant change compared to standard diet/PBS, \# indicates significant change compared to ADR-159/PBS.

$F(3,253)=137.887, p<0.0005]$, there was no difference in body weight of standard and ADR-159 fed animals dosed with either PBS or Citrobacter [repeated measures ANOVA, GreenhouseGeisser; $F(9,758)=1.547, p=0.131$; Figure 4]. Therefore, it was stipulated that a sufficient caloric intake was provided with ad libitum ADR-159 diet.

\section{ADR-159 Diet Does Not Prevent Citrobacter Infection}

After 4 weeks animals on both diets were orally dosed with either Citrobacter or PBS. Comparable levels of Citrobacter shedding were observed for both standard and ADR-159 fed animals [Greenhouse-Geisser test, time*treatment, $F_{(11)}=1.1418$, $p=0.332$; Figure 4]. A high heterogeneity was observed in both standard and ADR-159 fed animals regarding the initiation and rate of infection. However, in both groups the proportion of infected animals (as defined by shedding $10^{6} \mathrm{cfu} / \mathrm{g}$ feces) was not significantly different $\left[\chi^{2}(1)=0.9709, p=0.325\right.$ ) (Supplementary Figure S1). No Citrobacter was detected in the feces of PBS-dosed animals or animals before dosing.

\section{Impact of ADR-159 and Citrobacter Infection on Inflammation}

The ADR-159 diet had no effect on fecal lipocalin 2 (LCN2) levels over the initial 4 weeks of the trial (independent $t$-test; week 0 $t=1.354, p=0.183$; week $4 t=-0.852, p=0.399)$. Following the Citrobacter dosing significant changes were detected between groups after 12 [ANOVA, $F(3,44)=6.686, p=0.001$ ] and 18 days [ANOVA, $F(3,43)=12.203, p<0.0005$ ]. At 12 days post-dosing animals on standard diet dosed with Citrobacter had significantly increased LCN2 levels (post hoc Games-Howell, $p=0.011$ ). At the same time there was no difference between Citrobacter and PBS dosed animals on the ADR-159 diet (post hoc Games-Howell, $p=0.272$ ), nor between standard and ADR-159 fed animals dosed with PBS (post hoc Games-Howell, $p=0.113$ ). At sacrifice both standard (post hoc Games-Howell, $p=0.002$ ) and ADR159 (post hoc Games-Howell, $p=0.040$ ) fed animals dosed with Citrobacter had significantly higher LCN2 levels compared to their PBS-dosed counterparts (Figure 4).

\section{ADR-159 Prevents a Reduction of Small Intestine Length in Citrobacter Infected Animals}

The length of the small intestine differed between groups $[F(3$, $43)=7.681, p<0.0005$; Figure 5]. Citrobacter infection led to a reduction of small intestine length in standard fed animals (post hoc Bonferroni, $p=0.002$ ). In ADR-159 fed animals this reduction was not observed (post hoc Bonferroni, $p=0.188$ ). There was no significant difference in the mass of the small intestine $[F(3,43)=1.880, p=0.147]$, cecum $[F(3,40)=1.354$, $p=0.271]$ or colon length $[F(3,42)=1.525, p=0.222]$. In both standard and ADR-159 fed animals the colon weight increased in Citrobacter infected animals compared to healthy controls (Kruskal-Wallis Test, $p<0.0005$; post hoc Mann-Whitney $U$-test, $p<0.0005$ for both diets).

\section{ADR-159 Prevents an Increase of Colon Crypt Length in Citrobacter Infected Animals}

Colon crypt length differed between groups $[F(3,36)=10.552$, $p<0.0005$; Figure 5]. In standard fed animals the length of colon crypts increased in the Citrobacter infected animals (post hoc Bonferroni, $p<0.0005)$. In ADR-159 fed animals the colon crypt length was not affected by Citrobacter infection (post hoc Bonferroni, $p=0.267$ ). At the same time the length of ileum villi was not affected by infection and/or diet (Kruskal-Wallis Test, $p=0.052$ ).

\section{Colon Cytokine Expression Levels in Standard and ADR-159 Fed Mice}

Colons of ADR-159 fed animals had 0.49 times lower expression levels of IL-12 $\alpha$ (ANOVA, $p<0.0005$ ) compared to the colons of the standard fed animals. In contrast IL-17f (ANOVA, $p=0.0038$ ) expression levels in colons of ADR-159 fed animals were 2.38 times higher (Figure 6). No significant differences were observed for IL-12 $\beta$, IFN- $\gamma$, TNF, IL-1 $\beta$, IL-6, IL-18, IL-10, IL-22, IL-23 $\alpha$, and CXCL1 expression levels.

Expression levels in the colons of animals dosed with Citrobacter were expressed relative to PBS-dosed animals on the same diet. Citrobacter dosing in Standard fed animals led to a significant increase in IL-12 $\beta$ expression. Similarly, in ADR-159 fed animals, Citrobacter dosing also led to a significant increase 


\section{Small intestine}
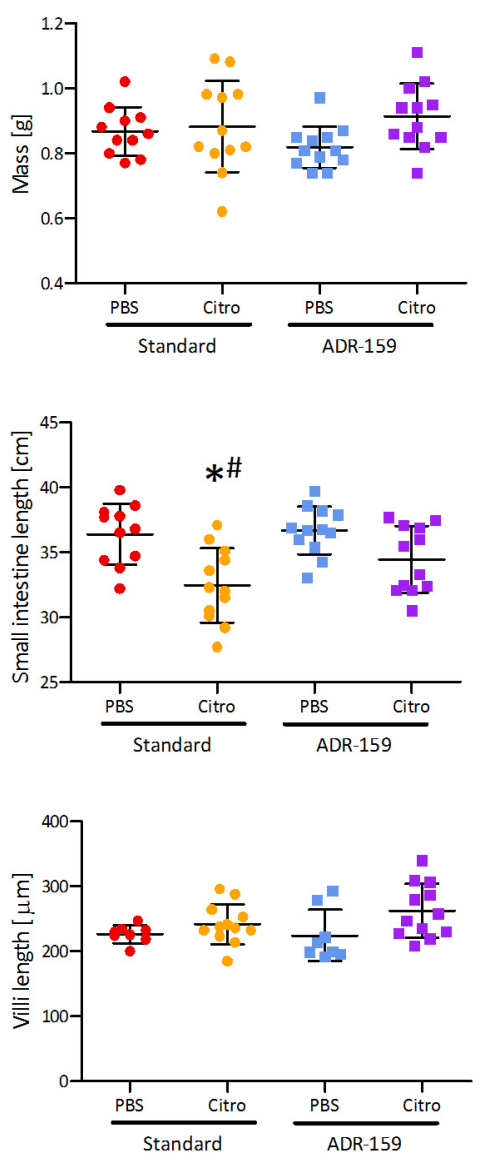

Caecum

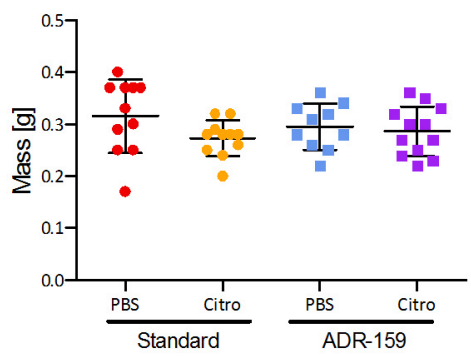

- Standard diet/ PBS

- Standard diet/ Citrobacter

- ADR-159 diet/PBS

- ADR-159 diet/ Citrobacter

* indicates significant increase compared standard diet / PBS

\# indicates significant change compared to ADR-159 / PBS

\section{Colon}
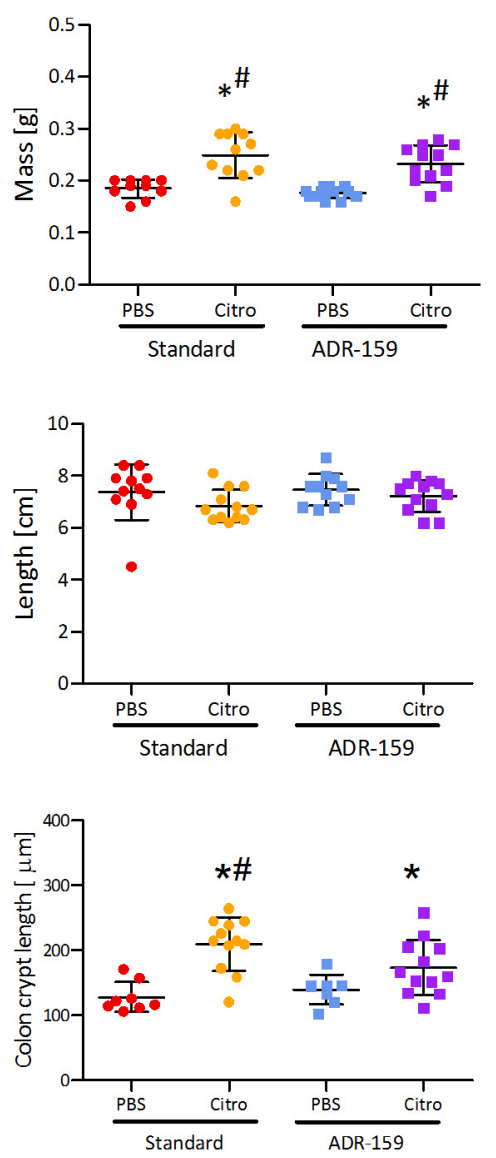

FIGURE 5 | Mass, total length, and villi/crypt length of internal organs of standard (circle) and ADR-159 (square) fed animals dosed with PBS (red, blue) or C. rodentium (orange, purple). Error bars represent SD. *Indicates significant increase compared to standard diet/PBS, \#Indicates significant change compared to ADR-159/PBS.

in IL-12 $\beta$ expression, but with additional increases in IFN- $\gamma$ and IL-22 (Figure 6). There was no significant difference in IL-12 $\alpha$, TNF, IL-17f, IL-1 $\beta$, IL-6, IL-18, IL-10, IL-23 $\alpha$, or CXCL1 expression level in the colons of animals dosed with Citrobacter on either of the diets.

\section{Cecum SCFA Levels in Standard and ADR-159 Fed Mice}

Total SCFA levels in the cecum differed between groups [oneway ANOVA; $F(3,42)=15.489, p<0.0005$; Figure 7]. In particular, ADR-159 fed animals had lower levels of propionate (post hoc Bonferroni, $p=0.017$ ), butyrate (post hoc GamesHowell, $p=0.015$ ) and valerate (post hoc Bonferroni, $p=0.014$ ) compared to standard fed animals. There was no effect of test conditions on levels of isobutyrate [one-way ANOVA; $F(3$, $42)=1.797, p=0.162$ ) and isovalerate [one-way ANOVA; $F(3$, $42)=2.988, p=0.042$; post hoc Bonferroni, $p>0.05]$. Overall, Citrobacter dosed animals had lower levels of acetate, butyrate and total SCFA as compared to their uninfected counterparts.

\section{DISCUSSION}

The objectives of this study were to evaluate the effects of ADR159 on the murine microbiome and on the susceptibility of mice to infection with the enteric pathogen $C$. rodentium and more specifically the impact on pathogen-induced inflammation and physiological changes associated with colitis. Female mice were fed standard chow or chow supplemented with 5\% ADR-159, a heat-treated co-fermentate of L. fermentum and L. delbrueckii. After 4 weeks of these diets, animals were dosed with either Citrobacter or PBS to evaluate the potential protective effect of ADR-159 on infection and pathogen-induced inflammatory damage.

Prolonged consumption of high doses of ADR-159 did not cause abnormalities in animal weight, length of intestines or weight of internal organs. The ADR-159 diet did not increase fecal LCN2 levels, which is used as a proxy for intestinal inflammation. The expression levels of the majority of the cytokines in the colon was not affected by ADR-159, but we did detect a significant increase in the expression of IL-17f (see 

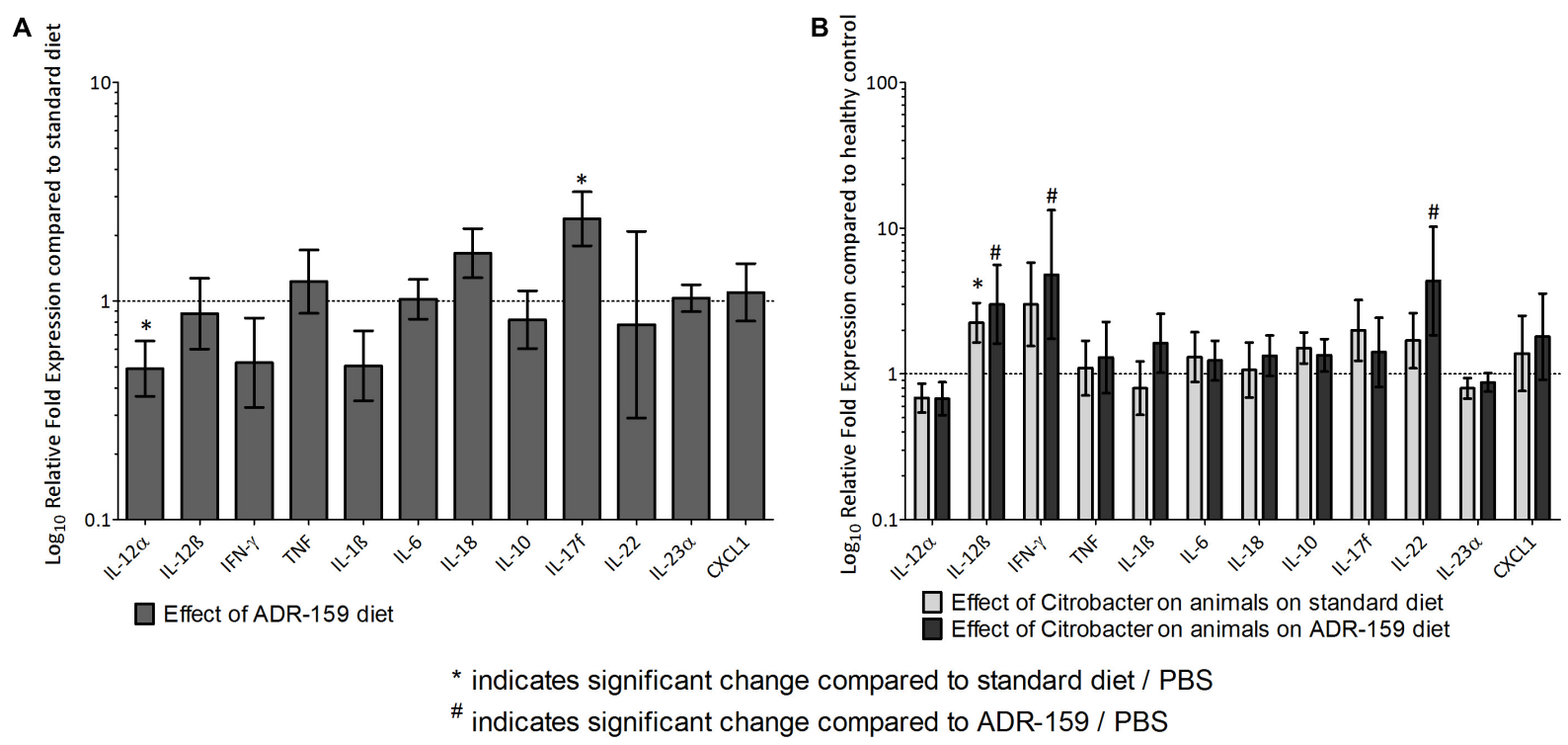

FIGURE 6 | (A) Gene expression levels in colon at sacrifice of ADR-159 fed animals dosed with PBS compared to standard fed animals (gray). Error bars represent 95\% confidence interval. Value 1 corresponds to no change in expression. *Indicates significant change compared to standard diet/PBS, \# indicates significant change compared to ADR-159/PBS. (B) Gene expression levels in colon at sacrifice of standard (light gray) and ADR-159 (dark gray) fed animals dosed with Citrobacter compared to their PBS dosed counterparts. Error bars represent $95 \%$ confidence interval. Value 1 corresponds to no change in expression. *Indicates significant change compared to standard diet/PBS, \#indicates significant change compared to ADR-159/PBS.

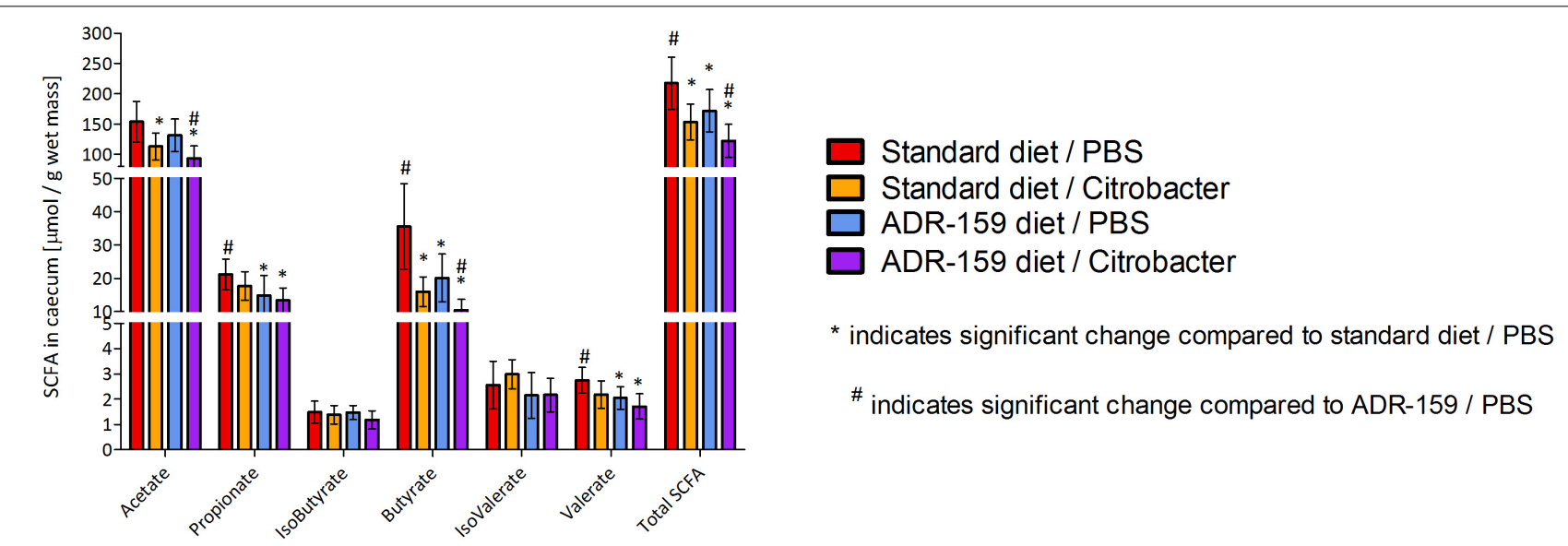

FIGURE 7 | SCFA concentration in cecum of standard (red, orange) and ADR-159 (blue, purple) fed animals dosed with PBS (red, blue) or C. rodentium (orange, purple). Error bars represent SD. *Indicates significant change compared to standard diet/PBS, \#indicates significant change compared to ADR-159/PBS.

below) and a reduced expression of IL-12 $\alpha$ (p35; see below) in ADR-159 fed animals.

The C. rodentium infection model is a well-established murine model which has been used previously to study bacterial pathogenesis, the health benefits of probiotics, mucosal immunology, and the role of the microbiome during infection (Crepin et al., 2016). Infection of mice with $C$. rodentium results in colonization of the large intestine and a subsequent mild inflammation that is maintained after the clearance of the pathogen (Wiles et al., 2004): consequently, the model is viewed as one that is relevant to IBD. During the Citrobacter infection phase we observed no effect of the ADR-159 diet on shedding of Citrobacter cells, suggesting there was no effect of ADR-159 on prevention of infection or the infection process: however, it should be noted that the high heterogeneity in initial infection observed in both the standard and ADR-159 fed animals obscures analysis.

\section{Effect of ADR-159 on Microbiome}

The microbiome of ADR-159 fed animals differed significantly from standard fed animals based on $16 \mathrm{~S}$ rDNA analysis. During the initial 4 weeks, the ADR-159 fed animals demonstrated a stable reduction of Turicibacter and Clostridium sensu stricto. Turicibacter has been associated with 2,4,6-trinitrobenzene 
sulfonic acid (TNBS)-induced colitis in mouse models (JonesHall et al., 2015) and with obesity/diabetes in mice (Horie et al., 2017). Members of Clostridium sensu stricto include, among others, pathogenic Clostridium botulinum, Clostridium perfringens, and Clostridium tetani (Gupta and Gao, 2009). The extent of the observed diet-induced microbiome shift was comparable to the previously observed change in male mice (Warda et al., 2018). However, the taxa affected in female mice differed compared to male mice (increase of Prevotella, reduction of Alistipes, and Odoribacter) possibly due to sex related microbiota differences.

Considering the limitations associated with utilization of $16 \mathrm{~S}$ rDNA (Poretsky et al., 2014) we aimed to improve the resolution of our analysis by studying the virome. The virome is comprised of both DNA and RNA viruses within a particular ecosystem including bacteriophage, viruses which target specific strains of bacteria. Thus, an analysis of the virome has the potential to provide better resolution than $16 \mathrm{~S}$ rDNA as bacteriophage levels may be indicative of the host strain fluctuations. The virome analysis further corroborated the subtle, but significant, impact of the ADR-159 diet on the microbiome.

Following the Citrobacter dosing, C. rodentium was detected in the microbiome of all animals dosed with the bacterium and, over time, the $C$. rodentium levels reduced. However, we did not observe a major disruption of the microbiome due to the infection at any of the time points. Nevertheless, we observed changes in the microbiota composition of ADR-159 fed animals dosed with Citrobacter: increased levels of Allobaculum and reduced levels of Bacteroides, Alistipes and unclassified Prevotellaceae, as compared to uninfected controls. Increased levels of Allobaculum have also been reported in mice receiving a probiotic mix (Lactobacillus acidophilus, Lactobacillus rhamnosus, and Bifidobacterium bifidum); this was associated with reduced colitis and tumor number after azoxymethane/DSS induction (Mendes et al., 2018). C. rodentium infection was previously shown to disrupt the intestinal microbiome (Lupp et al., 2007; Hoffmann et al., 2009). Citrobacter infection has been reported to trigger overgrowth of Enterobacteriaceae (most likely due to the fact that Citrobacter is a member of this group) (Lupp et al., 2007). Alternatively, Citrobacter infection increased the abundance of Proteobacteria, Clostridia, and Deferribacteres, and reduced Lactobacillaceae (Hoffmann et al., 2009). In our study, we did not observe an increase in Enterobacteriaceae (except the expected increase in $C$. rodentium), however, the diet-induced changes in the microbiome were maintained throughout the infection period.

\section{Effect of ADR-159 on Citrobacter-Induced Colitis}

We observed a marked reduction in physiological indicators of inflammation in Citrobacter dosed animals fed ADR-159. In comparison to standard fed animals, ADR-159 fed animals did not show a reduction of small intestine length or an increase of colon crypt length; these parameters are established indicators of gut inflammation in response to stressors (Kim et al., 2010). In line with the prevention of these morphological responses to
Citrobacter in ADR-159 animals, at 12 days post-initial dosing we did not observe an increase in the levels of fecal LCN2, as we did in standard fed animals. However, at sacrifice both ADR159 and standard-fed animals had elevated levels of fecal LCN2. LCN2 is commonly used as a sensitive inflammation indicator (Chassaing et al., 2012), yet it has been shown that LCN2 itself has a role in prevention of intestinal inflammation by enhancing pathogen clearance in macrophages (Toyonaga et al., 2016). Nonetheless, these findings suggest that localized Citrobacterinduced inflammation is lower in ADR-159 fed animals and has potentially a later onset (alternatively LCN2 response is delayed due to the lower initial inflammation), compared to standard fed animals.

In standard-fed animals at 18 days post-dosing with Citrobacter, only IL-12 $\beta$ (p40 subunit) was upregulated compared to PBS-dosed animals. However, in ADR-159 fed animals dosed with Citrobacter we also observed an increase of IFN- $\gamma$ and IL-22 (discussed below) compared to PBS-dosed ADR-159 fed animals. IL-12 $\beta$ deficient mice have been shown to be more sensitive to Citrobacter infection and also had increased colonic pathology (Simmons et al., 2002). IL-12 $\beta$ is a p40 subunit of heterodimeric IL-12 [heterodimer of p40 and p35 (IL-12 $\alpha$ )] and a subunit of IL-23 [heterodimer of $\mathrm{p} 40$ and $\mathrm{p} 19$ (IL-23 $\alpha$ )]. IL-12 production represents a powerful pro-inflammatory response to pathogenic microorganisms particularly, as it can induce NK cells to secrete IL-22 (Zenewicz and Flavell, 2011), and it is known to have a role in conferring resistance to C. rodentium (Ngo et al., 2018). IL-12 was also shown to trigger initiation of colitis while IL-23 drives the chronic disease phase (Eftychi et al., 2019) and it is one of the most potent inducers of IL-22. As IL-12 $\beta$ is up to 1000 times higher expressed than the IL-12-complementing IL-12 $\alpha$ subunit, free $\mathrm{p} 40$ or p 40 homodimers are commonly encountered (Zundler and Neurath, 2015; Behzadi et al., 2016). In particular, p40 homodimers have been shown to antagonize IL-12 activity in vitro and serve as a chemoattractant for macrophages and dendritic cell (DC) (Zundler and Neurath, 2015; Behzadi et al., 2016). We speculate that as levels of IL- $12 \alpha$ and IL-23 $\alpha$ were not affected by Citrobacter dosing regardless of the diet, the elevated levels of IL-12 $\beta$ would most likely lead to elevated levels of p40 homodimers.

The expression of IL-22 was induced in Citrobacter-dosed animals on the ADR-159 diet, but not on the standard diet (Figure 6). IL-22 belongs to the IL-10 cytokine family (Zenewicz and Flavell, 2011) and is produced in the intestinal mucosa by group 3 innate lymphoid cells (ILC3s; produces IL-22 during the early stage of infection) and CD $4+\mathrm{T}$ cells (including Th17 cells and Th22 cells; produces IL-22 during late stage of infection) (Ngo et al., 2018). C. rodentium infection is known to trigger the expression of IL-22, which is then able to confer resistance to $C$. rodentium by binding to $\mathrm{IL}-22 \mathrm{R}$, expressed by intestinal epithelial cells, and a resultant induction of mucin production. In addition, this binding also induces RegIII antimicrobial peptides, epithelial proliferation, and wound healing and repair mechanisms. The overall effect is a strengthening of barrier integrity (Ngo et al., 2018). The IL-22 response to C. rodentium infection seems to be dependent on IL-23 and a lymphotoxin pathway (Collins et al., 2014b). However, while we observed 
increased relative expression of IL-23 p40 (IL-12 $\beta$ ) subunit and no change in p19 (IL-23 $\alpha$ ) subunit; we cannot conclude on the IL-23 levels. Moreover, we did not observe increased expression of CXCL1, one of the chemokines known to recruit neutrophils to the lamina propria soon after infection (Koroleva et al., 2015), in Citrobacter dosed animals regardless of the diet, suggesting that IL-22 was upregulated via a different pathway.

Sample collection time could be one reason for the reduced number of differentially expressed cytokines, as a number of studies have reported that the peak response (IL-17a, IL-17f, IL-22, IL-1 $\beta$, TNF, and IFN- $\gamma$ ) is between 8 and 21 (Lupp et al., 2007; Hoffmann et al., 2009; Mondelaers et al., 2016) days post-dosing.

In PBS-dosed ADR-159 fed animals, we observed a reduced expression of IL-12 $\alpha$. IL-12 $\alpha$ (p35) is a subunit of a pleiotropic cytokine IL-12 (see above) and at the same time a subunit of IL-35 (together with IL-27 $\beta$ ), an immune-suppressing cytokine that has a role in inhibition of arthritis, asthma, and IBD (Behzadi et al., 2016; Bello et al., 2018). In view of these considerations, a reduced expression of IL- $12 \alpha$ in PBS-dosed ADR-159 fed animals could lead to dual effects, as both pro- and anti-inflammatory effects can be anticipated. Relevant to this is the fact that in PBS-dosed ADR-159 fed animals we did not detect altered levels of LCN2, which is a proxy for (sub-)colitis inflammation (Chassaing et al., 2012); indicating that we did not observe a pro-inflammatory effect in PBS-dosed ADR-159 fed animals.

We observed elevated levels of IL-17f in PBS-dosed ADR-159 fed animals. Although IL-17f is highly homologous to IL-17a and both of those cytokines bind to the same receptor, their functional roles differ (Ishigame et al., 2009). The primary function of IL-17f is in neutrophil recruitment and immunity to extracellular pathogens (bacterial and fungal), while IL-17a has a predominant role in autoimmune pathology (Gaffen, 2009; Ishigame et al., 2009; Tang et al., 2018). Protection against $C$. rodentium is known to require IL-17a and IL-17f (Ishigame et al., 2009; Collins et al., 2014b), however, IL-17f-deficient mice are resistant to dextran sodium sulfate (DSS)-induced colitis, presenting milder acute intestinal inflammation (Leppkes et al., 2009; Tang et al., 2018). Elevated levels of IL-17f in PBS-dosed ADR-159 fed animals may have the potential to enhance future resistance to pathogens: however, we did not observe reduced colonization/shedding of Citrobacter. It is possible that IL-17f levels may have not been elevated prior dosing or the levels reached were not at physiologically significant level. Moreover, the dual role of IL-17 may explain the lack of altered levels of IL-17f following the Citrobacter dosing regardless of the diet. Similarly, expression levels of IL-18, a pro-inflammatory cytokine involved in Th1 and Th2 responses and induction of cell-mediated immunity following exposure to microbial products including lipopolysaccharide (LPS) (Kaplanski, 2018), were unaffected by diet or by Citrobacter infection. Likewise, levels of IL-10, an essential anti-inflammatory cytokine reported to have important role as a negative regulator of immune responses to microbial antigens (Rutz and Ouyang, 2016), were not affected.

A number of pre-clinical and clinical interventions using prebiotics (Wilson and Whelan, 2017), probiotics (live bacteria)
(Thakur et al., 2016) as well as dead bacteria (Lin et al., 2007; Taverniti and Guglielmetti, 2011) have been shown to have an effect on infection and/or inflammation. In line with our observations galactooligosaccharide (GOS) supplementation was shown to reduce the Citrobacter-induced inflammation without affecting the initial infection (Kittana et al., 2018). Similarly, rectal dosing with $140 \mathrm{mM}$ butyrate did not affect Citrobacter infection but did reduce colon histopathological scores and hyperplasia (Jiminez et al., 2017). In our study ADR-159 fed animals had lower levels of total SCFA, in particular butyrate, propionate, and valerate. Citrobacter dosed animals had lower levels of acetate, butyrate and total SCFA regardless of the diet. SCFA production can contribute directly to host energy metabolism with acetate and propionate being absorbed and metabolized by the liver and peripheral organs (den Besten et al., 2013). While butyrate is mainly utilized by the colonic epithelium (den Besten et al., 2013; LeBlanc et al., 2017) and it can also be used by certain bacteria as an energy source. We did not observe an increase in chow consumption or changes in weight compared to standard fed animals, suggesting that the detected change in SCFA levels did not disturb energy levels. A number of studies have also reported SCFA levels that were far lower than those observed here as normal for C57 mice (Wang et al., 2016; Burokas et al., 2017). Although we observed a statistically significant change in SCFA in ADR-159 fed animals, this may not be physiologically relevant in a situation where there is no deficiency as was the case in our study. This is also supported by the overall positive effect that we saw in the gut in response to Citrobacter challenge.

It has previously been demonstrated that Citrobacter-induced crypt hyperplasia was reduced by daily treatment of mice with fermented dairy products containing Lactobacillus rhamnosus and two strains of Lactobacillus paracasei, yet this treatment did not affect $C$. rodentium colonization (Collins et al., 2014a). Interestingly, protection against Citrobacter-induced crypt hyperplasia required the presence of live bacteria (Collins et al., 2014a). Collins and colleagues (Collins et al., 2014a) associated this protective effect with preventing a reduction in the abundance of Turicibacter spp. and Ruminococcus spp. at the highest point of the C. rodentium infection (Collins et al., 2014a). Loss of both Turicibacter spp. and Ruminococcus spp. was previously associated with a sensitivity to dextran sodium sulfate (DSS)-induced colitis in mice (Zenewicz et al., 2013). In the current study, ADR-159 diet alone caused consistent reduction in Turicibacter spp. but not Ruminococcus spp., this was maintained after $C$. rodentium dosing. This indicates that reduction in a single taxa was not associated with hyperplasia and/or colitis, as uninfected animals had no observed signs of inflammation.

\section{CONCLUSION}

In conclusion, prolonged consumption of heat-treated lactobacilli (ADR-159) diet had no negative effect on general health. ADR-159 diet has an effect on microbiota composition and diversity in both male (Warda et al., 2018) and female (this study) mice. C. rodentium infection of female mice was not prevented by the ADR-159 diet: however, Citrobacter-induced 
inflammatory damage due to colitis was reduced. Simultaneously with the reduced Citrobacter-induced inflammation we saw induced expression of IL-12 $\beta$, IFN- $\gamma$, and IL-22, known to be involved in Citrobacter resistance (Ngo et al., 2018).

Our studies add to the existing body of knowledge regarding the impact of heat-treated microbes on the microbiome and on health. The limited number of studies in this field suggests a need for further research. The microbiological, histological, immunological and biochemical results outlined here provide new insights on the impact of heat-treated bacteria and their metabolites on the murine microbiome and health.

These results also indicate that further investigation of the potential therapeutic effects of ADR-159 in IBD are warranted.

\section{DATA AVAILABILITY STATEMENT}

The datasets generated for this study can be found in the Sequence Read Archive under the accession PRJNA545247.

\section{ETHICS STATEMENT}

The animal study was reviewed and approved by the Animal Experimentation Ethics Committee of University College Cork and Health Products Regulatory Authority under HPRA Project License AE19130/P060.

\section{AUTHOR CONTRIBUTIONS}

AW and $\mathrm{CH}$ contributed to the conception and design of the study. $\mathrm{CMH}$ and $\mathrm{AW}$ performed the animals

\section{REFERENCES}

Alipour, M., Lou, Y., Zimmerman, D., Bording-Jorgensen, M. W., Sergi, C., Liu, J. J., et al. (2013). A balanced IL-1beta activity is required for host response to Citrobacter rodentium infection. PLoS One 8:e80656. doi: 10.1371/journal.pone. 0080656

Allard, G., Ryan, F. J., Jeffery, I. B., and Claesson, M. J. (2015). SPINGO: a rapid species-classifier for microbial amplicon sequences. BMC Bioinformatics 16:324. doi: 10.1186/s12859-015-0747-1

Behzadi, P., Behzadi, E., and Ranjbar, R. (2016). IL-12 family cytokines: general characteristics, pathogenic microorganisms, receptors, and signalling pathways. Acta Microbiol. Immunol. Hung. 63, 1-25. doi: 10.1556/030.63.2016.1.1

Belizario, J. E., Faintuch, J., and Garay-Malpartida, M. (2018). Gut microbiome dysbiosis and immunometabolism: new frontiers for treatment of metabolic diseases. Mediators Inflamm. 2018:2037838. doi: 10.1155/2018/2037838

Bello, R. O., Chin, V. K., Abd Rachman Isnadi, M. F., Abd Majid, R., Atmadini Abdullah, M., Lee, T. Y., et al. (2018). The role, involvement and function(s) of interleukin-35 and interleukin-37 in disease pathogenesis. Int. J. Mol. Sci. 19:E1149. doi: 10.3390/ijms19041149

Bolger, A. M., Lohse, M., and Usadel, B. (2014). Trimmomatic: a flexible trimmer for Illumina sequence data. Bioinformatics 30, 2114-2120. doi: 10. 1093/bioinformatics/btu170

Burokas, A., Arboleya, S., Moloney, R. D., Peterson, V. L., Murphy, K., Clarke, G., et al. (2017). Targeting the microbiota-gut-brain axis: prebiotics have anxiolytic and antidepressant-like effects and reverse the impact of chronic stress in mice. Biol. Psychiatry 82, 472-487. doi: 10.1016/j.biopsych.2016. 12.031 experiment. AW, $\mathrm{PB}, \mathrm{CMH}$, and GD processed the samples. AC performed the analysis of microbiome and virome sequencing data. AW performed the statistical analysis and wrote the first draft of the manuscript. $\mathrm{CMH}$ and AC wrote sections of the manuscript. All authors contributed to manuscript revision, read, and approved the submitted version.

\section{FUNDING}

This research was funded by a research grant from Adare Pharmaceuticals. APC Microbiome Ireland was funded by a Research Centre grant from Science Foundation Ireland (SFI) under Grant No. SFI/12/RC/2273.

\section{ACKNOWLEDGMENTS}

We would like to acknowledge Adare Pharmaceuticals and Dr. Stephen Perrett for providing ADR-159 samples and constructive discussions. We would like to acknowledge Dr. Conall Strain for measurement of SCFA.

\section{SUPPLEMENTARY MATERIAL}

The Supplementary Material for this article can be found online at: https://www.frontiersin.org/articles/10.3389/fmicb. 2020.00069/full\#supplementary-material

Callahan, B. J., Mcmurdie, P. J., Rosen, M. J., Han, A. W., Johnson, A. J., and Holmes, S. P. (2016). DADA2: high-resolution sample inference from Illumina amplicon data. Nat. Methods 13, 581-583. doi: 10.1038/nmeth.3869

Chassaing, B., Srinivasan, G., Delgado, M. A., Young, A. N., Gewirtz, A. T., and Vijay-Kumar, M. (2012). Fecal lipocalin 2, a sensitive and broadly dynamic non-invasive biomarker for intestinal inflammation. PLoS One 7:e44328. doi: 10.1371/journal.pone.0044328

Chen, L., Deng, H., Cui, H., Fang, J., Zuo, Z., Deng, J., et al. (2018). Inflammatory responses and inflammation-associated diseases in organs. Oncotarget 9, 72047218. doi: 10.18632/oncotarget.23208

Collins, J. W., Chervaux, C., Raymond, B., Derrien, M., Brazeilles, R., Kosta, A., et al. (2014a). Fermented dairy products modulate Citrobacter rodentiuminduced colonic hyperplasia. J. Infect. Dis. 210, 1029-1041. doi: 10.1093/infdis/ jiu205

Collins, J. W., Keeney, K. M., Crepin, V. F., Rathinam, V. A., Fitzgerald, K. A., Finlay, B. B., et al. (2014b). Citrobacter rodentium: infection, inflammation and the microbiota. Nat. Rev. Microbiol. 12, 612-623. doi: 10.1038/nrmicro3315

Crepin, V. F., Collins, J. W., Habibzay, M., and Frankel, G. (2016). Citrobacter rodentium mouse model of bacterial infection. Nat. Protoc. 11, 1851-1876. doi: $10.1038 /$ nprot.2016.100

Dann, S. M., Spehlmann, M. E., Hammond, D. C., Iimura, M., Hase, K., Choi, L. J., et al. (2008). IL-6-dependent mucosal protection prevents establishment of a microbial niche for attaching/effacing lesion-forming enteric bacterial pathogens. J. Immunol. 180, 6816-6826. doi: 10.4049/jimmunol.180.10. 6816

de Almada, C. N., Almada, C. N., Martinez, R. C. R., and Sant'ana, A. S. (2016). Paraprobiotics: evidences on their ability to modify biological responses, 
inactivation methods and perspectives on their application in foods. Trends Food Sci. Technol. 58, 96-114. doi: 10.1016/j.tifs.2016.09.011

den Besten, G., Van Eunen, K., Groen, A. K., Venema, K., Reijngoud, D. J., and Bakker, B. M. (2013). The role of short-chain fatty acids in the interplay between diet, gut microbiota, and host energy metabolism. J. Lipid Res. 54, 2325-2340. doi: 10.1194/jlr.R036012

Dinan, T. G., and Cryan, J. F. (2017). The microbiome-gut-brain axis in health and disease. Gastroenterol. Clin. North Am. 46, 77-89. doi: 10.1016/j.gtc.2016. 09.007

Edgar, R. C., Haas, B. J., Clemente, J. C., Quince, C., and Knight, R. (2011). UCHIME improves sensitivity and speed of chimera detection. Bioinformatics 27, 2194-2200. doi: 10.1093/bioinformatics/btr381

Eftychi, C., Schwarzer, R., Vlantis, K., Wachsmuth, L., Basic, M., Wagle, P., et al. (2019). Temporally distinct functions of the cytokines IL-12 and IL-23 drive chronic colon inflammation in response to intestinal barrier impairment. Immunity 51, 367-380.e4. doi: 10.1016/j.immuni.2019.06.008

Ferrero-Miliani, L., Nielsen, O. H., Andersen, P. S., and Girardin, S. E. (2007). Chronic inflammation: importance of NOD2 and NALP3 in interleukin-1beta generation. Clin. Exp. Immunol. 147, 227-235.

Gaffen, S. L. (2009). Structure and signalling in the IL-17 receptor family. Nat. Rev. Immunol. 9, 556-567. doi: 10.1038/nri2586

Giron, F., and Quigley, E. M. M. (2018). Pharmabiotic manipulation of the microbiota in gastrointestinal disorders: a clinical perspective. J. Neurogastroenterol. Motil. 24, 355-366. doi: 10.5056/jnm18004

Grazziotin, A. L., Koonin, E. V., and Kristensen, D. M. (2017). Prokaryotic virus orthologous groups (pVOGs): a resource for comparative genomics and protein family annotation. Nucleic Acids Res. 45, D491-D498. doi: 10.1093/nar/gkw975

Guerin, E., Shkoporov, A., Stockdale, S. R., Clooney, A. G., Ryan, F. J., Sutton, T. D. S., et al. (2018). Biology and taxonomy of crAss-like bacteriophages, the most abundant virus in the human gut. Cell Host Microbe 24, 653-664.e6. doi: 10.1016/j.chom.2018.10.002

Gupta, R. S., and Gao, B. (2009). Phylogenomic analyses of clostridia and identification of novel protein signatures that are specific to the genus Clostridium sensu stricto (cluster I). Int. J. Syst. Evol. Microbiol. 59, 285-294. doi: 10.1099/ijs.0.001792-0

Hellemans, J., Mortier, G., De Paepe, A., Speleman, F., and Vandesompele, J. (2007). qBase relative quantification framework and software for management and automated analysis of real-time quantitative PCR data. Genome Biol. 8:R19.

Higgins, L. M., Frankel, G., Douce, G., Dougan, G., and Macdonald, T. T. (1999). Citrobacter rodentium infection in mice elicits a mucosal Th1 cytokine response and lesions similar to those in murine inflammatory bowel disease. Infect. Immun. 67, 3031-3039. doi: 10.1128/iai.67.6.3031-3039.1999

Hoffmann, C., Hill, D. A., Minkah, N., Kirn, T., Troy, A., Artis, D., et al. (2009). Community-wide response of the gut microbiota to enteropathogenic Citrobacter rodentium infection revealed by deep sequencing. Infect. Immun. 77, 4668-4678. doi: 10.1128/IAI.00493-09

Holder, M. K., Peters, N. V., Whylings, J., Fields, C. T., Gewirtz, A. T., Chassaing, B., et al. (2019). Dietary emulsifiers consumption alters anxiety-like and socialrelated behaviors in mice in a sex-dependent manner. Sci. Rep. 9:172. doi: 10.1038/s41598-018-36890-3

Horie, M., Miura, T., Hirakata, S., Hosoyama, A., Sugino, S., Umeno, A., et al. (2017). Comparative analysis of the intestinal flora in type 2 diabetes and nondiabetic mice. Exp. Anim. 66, 405-416. doi: 10.1538/expanim.17-0021

Ishigame, H., Kakuta, S., Nagai, T., Kadoki, M., Nambu, A., Komiyama, Y., et al. (2009). Differential roles of interleukin-17A and $-17 \mathrm{~F}$ in host defense against mucoepithelial bacterial infection and allergic responses. Immunity 30, 108-119. doi: 10.1016/j.immuni.2008.11.009

Jiminez, J. A., Uwiera, T. C., Abbott, D. W., Uwiera, R. R. E., and Inglis, G. D. (2017). Butyrate supplementation at high concentrations alters enteric bacterial communities and reduces intestinal inflammation in mice infected with Citrobacter rodentium. mSphere 2:e00243-17. doi: 10.1128/mSphere.002 43-17

Jiminez, J. A., Uwiera, T. C., Douglas Inglis, G., and Uwiera, R. R. (2015). Animal models to study acute and chronic intestinal inflammation in mammals. Gut Pathog. 7:29.

Jones-Hall, Y. L., Kozik, A., and Nakatsu, C. (2015). Ablation of tumor necrosis factor is associated with decreased inflammation and alterations of the microbiota in a mouse model of inflammatory bowel disease. PLoS One 10:e0119441. doi: 10.1371/journal.pone.0119441

Kaplanski, G. (2018). Interleukin-18: biological properties and role in disease pathogenesis. Immunol. Rev. 281, 138-153. doi: 10.1111/imr.12616

Kelly, J. R., Minuto, C., Cryan, J. F., Clarke, G., and Dinan, T. G. (2017). Cross talk: the microbiota and neurodevelopmental disorders. Front. Neurosci. 11:490. doi: 10.3389/fnins.2017.00490

Kim, M., Ashida, H., Ogawa, M., Yoshikawa, Y., Mimuro, H., and Sasakawa, C. (2010). Bacterial interactions with the host epithelium. Cell Host Microbe 8, 20-35. doi: 10.1016/j.chom.2010.06.006

Kittana, H., Quintero-Villegas, M. I., Bindels, L. B., Gomes-Neto, J. C., Schmaltz, R. J., Segura Munoz, R. R., et al. (2018). Galactooligosaccharide supplementation provides protection against Citrobacter rodentium-induced colitis without limiting pathogen burden. Microbiology 164, 154-162. doi: 10. 1099/mic.0.000593

Koroleva, E. P., Halperin, S., Gubernatorova, E. O., Macho-Fernandez, E., Spencer, C. M., and Tumanov, A. V. (2015). Citrobacter rodentium-induced colitis: a robust model to study mucosal immune responses in the gut. J. Immunol. Methods 421, 61-72. doi: 10.1016/j.jim.2015.02.003

LeBlanc, J. G., Chain, F., Martin, R., Bermudez-Humaran, L. G., Courau, S., and Langella, P. (2017). Beneficial effects on host energy metabolism of shortchain fatty acids and vitamins produced by commensal and probiotic bacteria. Microb. Cell Fact. 16:79. doi: 10.1186/s12934-017-0691-z

Leppkes, M., Becker, C., Ivanov, I. I., Hirth, S., Wirtz, S., et al. (2009). RORgammaexpressing Th17 cells induce murine chronic intestinal inflammation via redundant effects of IL-17A and IL-17F. Gastroenterology 136, 257-267. doi: 10.1053/j.gastro.2008.10.018

Li, J., Casanova, J. L., and Puel, A. (2018). Mucocutaneous IL-17 immunity in mice and humans: host defense vs. excessive inflammation. Mucosal Immunol. 11, 581-589. doi: 10.1038/mi.2017.97

Lin, W. H., Yu, B., Lin, C. K., Hwang, W. Z., and Tsen, H. Y. (2007). Immune effect of heat-killed multistrain of Lactobacillus acidophilus against Salmonella typhimurium invasion to mice. J. Appl. Microbiol. 102, 22-31. doi: 10.1111/j. 1365-2672.2006.03073.x

Livak, K. J., and Schmittgen, T. D. (2001). Analysis of relative gene expression data using real-time quantitative PCR and the 2(-delta delta C(T)) method. Methods 25, 402-408. doi: 10.1006/meth.2001.1262

Love, M. I., Huber, W., and Anders, S. (2014). Moderated estimation of fold change and dispersion for RNA-seq data with DESeq2. Genome Biol. 15:550.

Lupp, C., Robertson, M. L., Wickham, M. E., Sekirov, I., Champion, O. L., Gaynor, E. C., et al. (2007). Host-mediated inflammation disrupts the intestinal microbiota and promotes the overgrowth of Enterobacteriaceae. Cell Host Microbe 2, 119-129. doi: 10.1016/j.chom.2007.06.010

Mangan, P. R., Harrington, L. E., O’quinn, D. B., Helms, W. S., Bullard, D. C., Elson, C. O., et al. (2006). Transforming growth factor-beta induces development of the $\mathrm{T}(\mathrm{H}) 17$ lineage. Nature 441, 231-234.

McMurdie, P. J., and Holmes, S. (2013). phyloseq: an R package for reproducible interactive analysis and graphics of microbiome census data. PLoS One 8:e61217. doi: 10.1371/journal.pone.0061217

Mehta, A. K., Gracias, D. T., and Croft, M. (2018). TNF activity and T cells. Cytokine 101, 14-18. doi: 10.1016/j.cyto.2016.08.003

Mendes, M. C. S., Paulino, D. S., Brambilla, S. R., Camargo, J. A., Persinoti, G. F., and Carvalheira, J. B. C. (2018). Microbiota modification by probiotic supplementation reduces colitis associated colon cancer in mice. World J. Gastroenterol. 24, 1995-2008. doi: 10.3748/wjg.v24.i18.1995

Mondelaers, S. U., Theofanous, S. A., Florens, M. V., Perna, E., AguileraLizarraga, J., Boeckxstaens, G. E., et al. (2016). Effect of genetic background and postinfectious stress on visceral sensitivity in Citrobacter rodentium-infected mice. Neurogastroenterol. Motil. 28, 647-658. doi: 10.1111/nmo.12759

Ngo, V. L., Abo, H., Maxim, E., Harusato, A., Geem, D., Medina-Contreras, O., et al. (2018). A cytokine network involving IL-36gamma, IL-23, and IL-22 promotes antimicrobial defense and recovery from intestinal barrier damage. Proc. Natl. Acad. Sci. U.S.A. 115, E5076-E5085. doi: 10.1073/pnas.1718902115

Nurk, S., Meleshko, D., Korobeynikov, A., and Pevzner, P. A. (2017). metaSPAdes: a new versatile metagenomic assembler. Genome Res. 27, 824-834. doi: 10.1101/ gr.213959.116

Papaconstantinou, H. T., and Thomas, J. S. (2007). Bacterial colitis. Clin. Colon Rectal Surg. 20, 18-27. doi: 10.1055/s-2007-970196 
Pedersen, H. K., Gudmundsdottir, V., Nielsen, H. B., Hyotylainen, T., Nielsen, T., Jensen, B. A., et al. (2016). Human gut microbes impact host serum metabolome and insulin sensitivity. Nature 535, 376-381. doi: 10.1038/nature18646

Poretsky, R., Rodriguez, R. L., Luo, C., Tsementzi, D., and Konstantinidis, K. T. (2014). Strengths and limitations of $16 \mathrm{~S}$ rRNA gene amplicon sequencing in revealing temporal microbial community dynamics. PLoS One 9:e93827. doi: 10.1371/journal.pone.0093827

Roux, S., Enault, F., Hurwitz, B. L., and Sullivan, M. B. (2015). VirSorter: mining viral signal from microbial genomic data. PeerJ 3:e985. doi: 10.7717/peerj.985

Rubin, D. C., Shaker, A., and Levin, M. S. (2012). Chronic intestinal inflammation: inflammatory bowel disease and colitis-associated colon cancer. Front. Immunol. 3:107. doi: 10.3389/fimmu.2012.00107

Rutz, S., and Ouyang, W. (2016). Regulation of interleukin-10 expression. Adv. Exp. Med. Biol. 941, 89-116. doi: 10.1007/978-94-024-0921-5_5

Shkoporov, A. N., Ryan, F. J., Draper, L. A., Forde, A., Stockdale, S. R., Daly, K. M., et al. (2018). Reproducible protocols for metagenomic analysis of human faecal phageomes. Microbiome 6:68. doi: 10.1186/s40168-0180446-z

Simmons, C. P., Goncalves, N. S., Ghaem-Maghami, M., Bajaj-Elliott, M., Clare, S., Neves, B., et al. (2002). Impaired resistance and enhanced pathology during infection with a noninvasive, attaching-effacing enteric bacterial pathogen, Citrobacter rodentium, in mice lacking IL-12 or IFN-gamma. J. Immunol. 168, 1804-1812. doi: 10.4049/jimmunol.168.4.1804

Tang, C., Kakuta, S., Shimizu, K., Kadoki, M., Kamiya, T., Shimazu, T., et al. (2018). Suppression of IL-17F, but not of IL-17A, provides protection against colitis by inducing Treg cells through modification of the intestinal microbiota. Nat. Immunol. 19, 755-765. doi: 10.1038/s41590-018-0134-y

Tatusov, R. L., Galperin, M. Y., Natale, D. A., and Koonin, E. V. (2000). The COG database: a tool for genome-scale analysis of protein functions and evolution. Nucleic Acids Res. 28, 33-36. doi: 10.1093/nar/28.1.33

Taverniti, V., and Guglielmetti, S. (2011). The immunomodulatory properties of probiotic microorganisms beyond their viability (ghost probiotics: proposal of paraprobiotic concept). Genes Nutr. 6, 261-274. doi: 10.1007/s12263-0110218-x

Thakur, B. K., Saha, P., Banik, G., Saha, D. R., Grover, S., Batish, V. K., et al. (2016). Live and heat-killed probiotic Lactobacillus casei Lbs2 protects from experimental colitis through Toll-like receptor 2-dependent induction of T-regulatory response. Int. Immunopharmacol. 36, 39-50. doi: 10.1016/j.intimp. 2016.03.033

Toyonaga, T., Matsuura, M., Mori, K., Honzawa, Y., Minami, N., Yamada, S., et al. (2016). Lipocalin 2 prevents intestinal inflammation by enhancing phagocytic bacterial clearance in macrophages. Sci. Rep. 6:35014. doi: 10.1038/srep35014
Vandesompele, J., De Preter, K., Pattyn, F., Poppe, B., Van Roy, N., De Paepe, A., et al. (2002). Accurate normalization of real-time quantitative RT-PCR data by geometric averaging of multiple internal control genes. Genome Biol. 3:Research0034.

Wang, H., Shi, P., Zuo, L., Dong, J., Zhao, J., Liu, Q., et al. (2016). Dietary nondigestible polysaccharides ameliorate intestinal epithelial barrier dysfunction in IL-10 knockout mice. J. Crohns Colitis 10, 1076-1086. doi: 10.1093/ecco-jcc/ jjw065

Warda, A. K., Rea, K., Fitzgerald, P., Hueston, C., Gonzalez-Tortuero, E., Dinan, T. G., et al. (2018). Heat-killed lactobacilli alter both microbiota composition and behaviour. Behav. Brain Res. 362, 213-223. doi: 10.1016/j.bbr.2018.12.047

Weingarden, A. R., and Vaughn, B. P. (2017). Intestinal microbiota, fecal microbiota transplantation, and inflammatory bowel disease. Gut Microbes 8, 238-252. doi: 10.1080/19490976.2017.1290757

Wiles, S., Clare, S., Harker, J., Huett, A., Young, D., Dougan, G., et al. (2004). Organ specificity, colonization and clearance dynamics in vivo following oral challenges with the murine pathogen Citrobacter rodentium. Cell Microbiol. 6, 963-972. doi: 10.1111/j.1462-5822.2004.00414.x

Wilson, B., and Whelan, K. (2017). Prebiotic inulin-type fructans and galacto-oligosaccharides: definition, specificity, function, and application in gastrointestinal disorders. J. Gastroenterol. Hepatol. 32(Suppl. 1), 64-68. doi: 10.1111/jgh.13700

Zenewicz, L. A., and Flavell, R. A. (2011). Recent advances in IL-22 biology. Int. Immunol. 23, 159-163. doi: 10.1093/intimm/dxr001

Zenewicz, L. A., Yin, X., Wang, G., Elinav, E., Hao, L., Zhao, L., et al. (2013). IL-22 deficiency alters colonic microbiota to be transmissible and colitogenic. J. Immunol. 190, 5306-5312. doi: 10.4049/jimmunol.1300016

Zundler, S., and Neurath, M. F. (2015). Interleukin-12: functional activities and implications for disease. Cytokine Growth Factor Rev. 26, 559-568. doi: 10. 1016/j.cytogfr.2015.07.003

Conflict of Interest: Adare Pharmaceutical provided funding for the study. Adare Pharmaceuticals was involved in study design, and in the decision to submit the article for publication, but not in the collection, analysis and interpretation of data.

Copyright (c) 2020 Warda, de Almeida Bettio, Hueston, Di Benedetto, Clooney and Hill. This is an open-access article distributed under the terms of the Creative Commons Attribution License (CC BY). The use, distribution or reproduction in other forums is permitted, provided the original author(s) and the copyright owner(s) are credited and that the original publication in this journal is cited, in accordance with accepted academic practice. No use, distribution or reproduction is permitted which does not comply with these terms. 